Florida International University FIU Digital Commons

4-27-2015

\title{
The Impact of Red Light Cameras on Injury Crashes within Miami-Dade County, Florida
}

Anthoni Llau

allauj01@fiu.edu

DOI: 10.25148 /etd.FIDC000059

Follow this and additional works at: https://digitalcommons.fiu.edu/etd

Part of the Epidemiology Commons

\section{Recommended Citation}

Llau, Anthoni, "The Impact of Red Light Cameras on Injury Crashes within Miami-Dade County, Florida" (2015). FIU Electronic Theses and Dissertations. 2240.

https://digitalcommons.fiu.edu/etd/2240

This work is brought to you for free and open access by the University Graduate School at FIU Digital Commons. It has been accepted for inclusion in FIU Electronic Theses and Dissertations by an authorized administrator of FIU Digital Commons. For more information, please contact dcc@fiu.edu. 


\section{FLORIDA INTERNATIONAL UNIVERSITY}

Miami, Florida

\section{THE IMPACT OF RED LIGHT CAMERAS ON INJURY CRASHES WITHIN}

\section{MIAMI-DADE COUNTY, FLORIDA}

A dissertation submitted in partial fulfillment of the

requirements for the degree of

DOCTOR OF PHILOSOPHY

in

PUBLIC HEALTH

by

Anthoni F Llau Jr

2015 
To: $\quad$ Interim Dean Mark L. Williams

Robert Stempel College of Public Health and Social Work

This dissertation, written by Anthoni F Llau Jr, and entitled The Impact of Red Light

Cameras on Injury Crashes within Miami-Dade County, Florida, having been approved in respect to style and intellectual content, is referred to you for judgment.

We have read this dissertation and recommend that it be approved.

Fabian G Cevallos

Vukosava Pekovic

Nasar U Ahmed, Major Professor

Date of Defense: April 27, 2015

The dissertation of Anthoni F Llau Jr is approved.

Interim Dean Mark L. Williams Robert Stempel College of Public Health and Social Work

Lakshmi N. Reddi

University Graduate School

Florida International University, 2015 
C Copyright 2015 by Anthoni F Llau Jr

All rights reserved. 


\section{DEDICATION}

I dedicate my dissertation work to my loving family. To my loving parents, Anthoni and Margot whose love, sacrifices, and words of encouragement allowed me to believe that all goals and dreams were possible with hard work and commitment. To my amazing wife Brenda, who was by my side throughout the entire doctoral program and who has always given me all the love and encouragement anyone could ask. She was my cheerleader, and I would not have started nor completed the program without her. To my sisters Jennifer and Melissa and brother Eric, who were always there for me when needed. To my niece and nephews Nicole, Michael, Matthew, Gabriel, Kevin, and Jacob, I wish for you to always strive for greatness no matter what obstacles are in your way. 


\section{ACKNOWLEDGMENTS}

I gratefully acknowledge the support and encouragement of my mentor and major professor, Dr. Nasar U Ahmed whose belief in my abilities helped sustain me through this process. I wish to thank the members of my committee, Dr. Hafiz Khan, Dr. Fabian Cevallos, and Dr. Vukosava Pekovic for their valuable advice and time commitment. I am thankful to Dr. Wasim Maziak for all his support and encouragement throughout my doctoral program. 


\section{ABSTRACT OF THE DISSERTATION \\ THE IMPACT OF RED LIGHT CAMERAS ON INJURY CRASHES WITHIN MIAMI-DADE COUNTY, FLORIDA}

by

Anthoni F Llau Jr

Florida International University, 2015

Miami, Florida

\section{Professor Nasar U Ahmed, Major Professor}

Previous red light camera (RLC) studies have shown reductions in violations and overall and right angle collisions, however, they may also result in increases in rear-end crashes (Retting \& Kyrychenko, 2002; Retting \& Ferguson, 2003). Despite their apparent effectiveness, many RLC studies have produced imprecise findings due to inappropriate study designs and/or statistical techniques to control for biases (Retting \& Kyrychenko, 2002), therefore, a more comprehensive approach is needed to accurately assess whether they reduce motor vehicle injury collisions. The objective of this proposal is to assess whether RLC's improve safety at signalized intersections within Miami-Dade County, Florida. Twenty signalized intersections with RLC's initiating enforcement on January 1st, 2011 were matched to two comparison sites located at least two miles from camera sites to minimize spillover effect. An Empirical Bayes analysis was used to account for regression to the mean. Incidences of all injury, red light running related injury, rightangle/turning, and rear-end collisions were examined. An index of effectiveness along with 95\% CI's were calculated. 
During the first year of camera enforcement, RLC sites experienced a marginal decrease in right-angle/turn collisions, a significant increase in rear-end collisions, and significant decreases in all-injury and red light running-related injury collisions. An increase in right-angle/turning and rear-end collisions at the RLC sites was observed after two years despite camera enforcement. A significant reduction in red light runningrelated injury crashes, however, was still observed after two years. A non-significant decline in all injury collisions was also noted.

Findings of this research indicate RLC's reduced red light running-related injury collisions at camera sites, yet its tradeoff was a large increase in rear-end collisions. Further, there was inconclusive evidence whether RLC's affected right-angle/turning and all injury collisions. Statutory changes in crash reporting during the second year of camera enforcement affected the incidence of right-angle and rear-end collisions, nevertheless, a novelty effect could not be ruled out. A limitation of this study was the small number of injury crashes at each site. In conclusion, future research should consider events such as low frequencies of severe injury/fatal collisions and changes in crash reporting requirements when conducting RLC analyses. 


\section{TABLE OF CONTENTS}

CHAPTER

PAGE

I. INTRODUCTION

Overview and public health significance

Study Rationale

Research Objectives

Specific Aims

References

II. MANUSCRIPT 1 - LITERATURE REVIEW (PUBLISHED)

Red Light Cameras in the United States - A Systematic Literature Review

Abstract

Introduction

Methods

Results

Discussion

References

Figures and Tables

III. MANUSCRIPT 2 - STATISTICAL METHODOLOGY

(PUBLICATION ACCEPTED)

Identification of an accident prediction model for red light camera analyses

Abstract

Introduction

51

Methods

Results

Discussion

References

Figures and Tables

IV MANUSCRIPT 3 - PRIMARY STUDY (ACCEPTED, IN PRESS)

Impact of Red Light Cameras on Motor Vehicle Injury Collisions

within Miami-Dade County, Florida

70

Abstract

71

Introduction

Methods

Results

Discussion

85

References

89

Figures and Tables 
V. CONCLUSIONS 97

Directions for future research 99

$\begin{array}{ll}\text { VI. LIST OF REFERENCES } & 100\end{array}$

$\begin{array}{lr}\text { VITA } & 109\end{array}$ 


\section{LIST OF TABLES}

TABLE

PAGE

Table 1.1 Manuscript 1:

U.S. studies of effects of red light cameras on violations

Table 1.2 Manuscript 1:

U.S. studies of effects of red light cameras on crashes

Table 1.3 Manuscript 1:

U.S. studies of effects of red light cameras on injuries

Table 2.1 Manuscript 2:

Intersection characteristics for development of accident prediction model

Table 2.2 Manuscript 2:

Safety performance function Poisson regression parameter estimates

Table 2.3 Manuscript 2:

Safety performance function negative binomial regression parameter estimates

Table 2.4 Manuscript 2:

Safety performance function gamma regression parameter estimates

Table 2.5 Manuscript 2:

Results of model goodness of fit tests for safety performance functions

Table 3.1 Manuscript 3:

Intersection characteristics of red light camera and comparison sites used for Empirical Bayes analysis

Table 3.2 Manuscript 3:

Mean crash frequency for red light camera and comparison sites during before and after periods

Table 3.3 Manuscript 3:

Safety performance functions for comparison signalized intersections used in Empirical Bayes analysis 
Table 3.4 Manuscript 3:

Safety effectiveness of red light camera sites by collision type 


\section{ACRONYMS AND ABBREVIATIONS}

MVC - Motor Vehicle Crashes

CDC - Centers for Disease Control and Prevention

WHO - World Health Organization

NHTSA - National Highway Traffic Safety Administration

SES - Socioeconomic Status

FHA - Federal Highway Administration

RLC - Red light camera

RTM - Regression to the mean

AADT - Annual Average Daily Traffic

SPF - Safety Performance Function

DUI - Driving Under the Influence

RLR - Red light running

EB - Empirical Bayes

IIHS - Insurance Institute for Highway Safety

GOF - Goodness of Fit

AIC - Akaike Information Criterion

DF - Degrees of Freedom

GIS - Geographic Information Systems

RCI - Roadway Characteristics Inventory

FDOT - Florida Department of Transportation

FTCRD - Florida Traffic Crash Records Database

NB - Negative Binomial 


\section{CHAPTER I \\ INTRODUCTION}

\section{Overview and public health significance}

In the United States, motor vehicle crashes (MVCs) are the leading cause of death among individuals aged 5-34 years (Centers for Disease Control and Prevention [CDC], 2011a). Within this age group, 13,388 persons were killed as the result of MVCs during 2010 , representing $17 \%$ of overall deaths and $27 \%$ of injury-related deaths. In addition, more than 2.3 million U.S. adult drivers and passengers were treated in emergency departments during 2009 (CDC, 2011b). Deaths attributed to MVCs are expected to be the 5th greatest cause of mortality worldwide by 2030 (World Health Organization [WHO], 2013).

Traffic accidents have been associated with several risk factors including human, social, and transportation. Human factors such as alcohol consumption represented 31\% of all U.S. crash-related fatalities during 2011 (National Highway Traffic Safety Administration [NHTSA], 2012]. In addition, distracted driving, e.g., cell phone use while driving, as a factor in fatal accidents increased 60\% between 2005 and 2009 (NHTSA, 2010a). Low socioeconomic status (SES) may also play a role in MVCs. Studies have indicated that crash fatality rates are greater in lower SES groups, regardless of gender (Chen et al., 2010).

Although human and social factors contribute to MVCs, those related directly to transportation (e.g., road infrastructure, weather, etc.) account for the majority of accidents, particularly fatalities. Roads affect crash risk since they impact how drivers perceive their environment and provide instructions for road users (e.g., pedestrians, 
bicyclists, and motor vehicle drivers) via signs, pavement markings, and traffic controls. Intersections are road sections where crashes frequently occur since these are locations where at least two roads cross each other and driver actions result in potential vehicle conflicts (NHTSA, 2010b). Although intersections represent a small fraction $(10 \%)$ of the U.S. roadway system, a significantly large proportion of crashes occur at these locations (Federal Highway Administration [FHA], 2014). During 2008, approximately $40 \%$ of all U.S. crashes occurred at intersections, of which over half (52\%) took place at roads with traffic signals (NHTSA, 2010b). Furthermore, 32\% of traffic signal crashes resulted in at least one occupant injury. Despite national research and prevention efforts, $10 \%$ of fatal crashes occurred at signalized intersections during 2011, remaining unchanged since 2000 (NHTSA 2001; NHTSA, 2013).

Collision-related injuries at intersections result from the types of accidents that transpire in these road segments. Of the different types of collisions that occur at intersections, those with the highest risk of injury are right angle and left-turn crashes (Abdel-Aty \& Radwan, 2000). Right angle crashes, which occur between two vehicles on perpendicular approaches, account for $42 \%$ of fatal crashes at signalized intersections. Left turn crashes, which account for $21 \%$ of fatal crashes at signalized intersections, occur between vehicles on opposite approaches where one vehicle is turning left and the opposing vehicle is going straight (FHA, 2014).

Rear-end crashes are the most common type of collisions at signalized intersections. Specific causes of rear-end crashes may include a driver's inattention to other vehicles or following too closely. Rear-end crash risk is also associated with higher traffic volumes, slippery road surfaces, and higher speed limits (Yan et al., 2005). 
Although rear-end crashes tend to be less severe, they account for $8 \%$ of fatal crashes at intersections and may result in debilitating and long-lasting injuries such as whiplash (FHA, 2014).

Noncompliance with traffic control devices is a major factor contributing to MVCs at signalized intersections. Police-reported crashes from four urban areas reported "ran traffic control" (i.e., red light running) was the single most common cause of collisions, accounting for $22 \%$ of urban and $27 \%$ of all injury crashes (i.e. crashes with at least one injury), respectively (Retting et al., 1995). Red light runners are generally comprised of younger males, elderly adults, alcohol impaired drivers, and those with driving violation histories (Retting et al., 1999). Several interventions have been utilized to decrease the risk of red light running crashes including police enforcement, educational campaigns, and engineering modifications such as signal timing changes. Red light cameras (RLCs) are now increasingly being used to discourage red light runners and decrease related crashes. RLCs have been used internationally since the 1970's, while the first U.S. program was developed in the early 1990's (Retting \& Kyrychenko, 2002). They can assist in decreasing red light running by automatically photographing the license plates of drivers or vehicles that run red lights. Despite the use of RLCs in the U.S. since the 1990's, few studies have been published.

Most RLC studies lacking methodological rigor have produced imprecise findings since they have failed to adopt appropriate study design and/or employ proper statistical techniques to control for biases such as regression to the mean (RTM) and spillover ((Retting \& Kyrychenko, 2002), therefore, a more comprehensive approach is needed to accurately assess whether they are effective in reducing MVCs and related injuries. Other 
factors also need to be accounted for to enhance RLC analysis such as an intersection's geometric characteristics. Intersection characteristics commonly examined include annual average daily traffic, speed limits, and number of lanes.

The relationship between the speed limit and the frequency of motor vehicle collisions is a subject which has been widely examined. Road speed limits affect driving speed choices, which in turn, influence crash frequency and severity. Various studies have attempted to determine the impact of road speed limits on driving speed and the frequency of both traffic-related crashes and related injuries/fatalities. Many have concluded that higher speed limits result in greater driving speeds. Freedman and Esterlitz (1990) estimated an increase of 3 miles per hour (mph) for states that raised speed limits after the 1987 national maximum speed limit changes. They found that the proportion of vehicles exceeding $70 \mathrm{mph}$ nearly doubled and that speeds continued to increase during the years after speed limit increases. Retting and Greene (1997) found that the percentage of drivers exceeding $112.7 \mathrm{~km} / \mathrm{h}$ increased from 29 to 41 percent in Riverside, California and from 15 to 50 percent in Houston, Texas after speed limit increases. Elvik (2012) concluded that, in general, driving speed has a direct correlation to speed limits. Decreases in speed limits result in reductions of mean driving speed of traffic. In turn, higher speed limits bring about increases in mean driving speed.

Researchers have also examined the relationship between speed and motor vehicle collisions and related injuries/fatalities. Evidence clearly indicates that increases in speed (both absolute and relative among vehicles) leads to an increase in crashes and injury severity. In Florida, high speed limits on major roadways are correlated with high rearend crash frequencies (Wang and Abdel-Aty, 2006). Solomon (1964) measured the 
relationship between crash and severity by measuring injury rates and property damage per crash-involved vehicle. In both cases, higher speeds implied greater costs. He also calculated the fatality rate associated with speeds, which ranged from 1 to 2 crash/fatality odds for speeds below $88.5 \mathrm{~km} / \mathrm{h}$ to over $20 \mathrm{crash} /$ fatality odds for speeds of $112.7 \mathrm{~km} / \mathrm{h}$ and above. Joksch (1993) found that higher speeds increase injury severity at a rate faster than the increase in speed. Elvik (2008) has estimated that if speeding were eliminated, it would result in a $25 \%$ reduction in fatalities, and decreases in severe and minor injuries by $18 \%$ and $10 \%$ among road users, respectively. It has been concluded that the faster a vehicle is moving prior to colliding with another vehicle or stationary object, the greater the exchange of energy, resulting in increased crash severity (Shinar, 1998).

Despite this evidence, it is unclear whether speed limit changes result in differences in injury/fatal motor vehicle collisions. Speed limit increases in Utah resulted in significant increases in total fatal crash rates on high-speed $(60-65 \mathrm{mph})$ rural nonInterstate segments, yet, no change in fatality and injury crash rates were observed on rural nor urban Interstate segments (Vernon et al. 2004). Renski et al. (1999) concluded that augmenting speed limits from 55 to $60 \mathrm{mph}$ and from 55 to $65 \mathrm{mph}$ increased the probability of sustaining minor and non-incapacitating injuries. Elevating speed limits from 65 to $70 \mathrm{mph}$, however, did not have a significant effect on crash severity due to a limited number of fatal crashes to draw conclusive results. A study investigating the relationship between speed limit increases and fatal crashes on U.S. interstates found the frequency of fatal accidents on rural interstates increased in some, but not all states. A second round of speed limit increases, however, brought about smaller increases in fatal 
crashes at rural interstates and little to no change in urban intersections (Balkin and Ord, 2001).

It is believed by many researchers that greater numbers of lanes are associated with an increase in motor vehicle collision rates. Other studies, however, have found conflicting results. Milton and Mannering (1998) found a greater number of collisions after the number of lanes on rural roads were increased. Another study found increased collision rates were associated with higher numbers of lanes on urban roadways (AbdelAty and Radwan, 2000). An analysis of crash data in Illinois found that increased numbers of lanes were shown to increase traffic-related fatalities (Noland and Oh, 2004). Awadzi et al. (2008) examined predictors of injury/fatal motor vehicle collisions among younger (35 - 54 years of age) and older (65+ years of age) drivers using Fatality Analysis Reporting System data. It was determined that number of lanes was associated with a lower risk of both injuries and fatalities. Yet, crashes in single lane roads were associated with a decreased likelihood of injuries while collision fatalities were less likely in four to seven lane roads. In contrast, Council and Stewart (2000) found a $40-60 \%$ reduction in collisions after two lane roads were converted to four lanes.

Some studies have also examined the relationship between the number of lanes entering an intersection and motor vehicle collisions. Since a greater number of lanes infer larger traffic volumes, it is believed that the probability of sustaining possible injuries in crashes increases. A study examining overall characteristics of red light running crashes occurring in Florida between 1999 and 2001, found several crash factors including number of lanes were significantly associated with the risk of red light running crashes (Yan et al. 2005). Similar results were found within three Southeast cities in 
Virginia, whereby red light running rates on urban roads were higher for intersections with a greater number of lanes (Porter and England, 2000).

Collision rates can be thought as an effective method of measuring motor vehicle crash risk since exposure is considered. Collision rates are calculated by dividing the crash frequency for a period of time by the estimated average annual daily traffic (AADT) of vehicles entering for all approaches at a site (e.g. intersection) during the same time period. Collision rate provides an improvement for comparison of different sites than frequency alone. Using simple collision rates to determine high risk road sites, though, has several disadvantages. First, it is assumed that collision frequency and volume have a linear relationship, but research suggests that lower volumes can experience greater collision rates (Lord, Washington, and Ivan, 2005; Harwood et al. 2000). Therefore, the relationship between crash frequency and AADT is non-linear (Qin et al. 2004). Second, collision rates, as with collision frequency, do not consider collision severity. Sites with high collision rates may have relatively few casualty (fatal and injury) collisions. Finally, studies indicate that both exposure and risk may depend on not only AADT but additional factors, all of which interact with one another, therefore safety performance functions (SPF's) are developed to determine which variables contribute to motor vehicle collisions. Previous studies that develop SPF's to determine risk factors for motor vehicle collisions commonly include AADT as a variable of exposure. Hall and Hurtado (1992) analyzed the relationship between roadway congestion and the level of safety at 400 urban signalized intersections within Albuquerque, New Mexico. Three year historical crash data along with intersection traffic volumes were obtained for each intersection. Using a least-squares regression model, the authors determined that as total 
entering volume increased, there was a corresponding increase in crash frequency. When crash rate as a function of total entering volume was considered, the relationship was weak, however, still statistically significant. A study conducted by Mehta and Lou (2013) developed and calibrated SPF's for two-lane, two-way rural roads and four lane divided highways within Alabama. SPF's were developed using negative binomial and poisongamma regression models. The authors determined that the best SPF model described mean collision frequency as a function of AADT, road segment length, lane width, year, and speed limit. A second study by Brimley et al. (2012) developed and calibrated SPF's for rural two-lane two-way road segments in Utah using negative binomial regression models. Crash data from $2005-2007$ was obtained to develop and calibrate four SPF's. The authors found that AADT, road segment length and speed limit, and percentage of AADT composed of multiple-unit trucks were significantly correlated with motor vehicle collision frequency. Greibe (2003) created an accident model to predict the expected number of crashes at urban junctions within Denmark. The model was based on crash data at 1036 intersections. Generalized linear modeling was employed to relate accident frequency to predictor variables. It was found that although there was difficulty in achieving stable and significant explanatory variables, AADT explained more than $90 \%$ of the variation in motor vehicle crashes.

To properly evaluate these factors, the following proposal will address RTM, spillover effect, and other confounders to assess the effectiveness of RLCs within a major metropolitan area by addressing the following questions:

1: What methodologies have been employed in well-designed RLC studies?

2: What statistical models are the most appropriate when analyzing a RLC study? 
3: What is the effect of RLCs on the injury collision incidence?

\section{Study Rationale}

Studies examining the effect of RLC's have shown reductions in violations and overall and right angle collisions however they may also result in increases in rear-end crashes (Retting \& Kyrychenko, 2002; Retting \& Ferguson, 2003). Despite their apparent effectiveness, many RLC studies have failed to account for biases such as RTM and spillover effects. Many studies examined sites with RLC installation based on high violation, crash, or crash-related injury history. A criterion for RLC implementation is to select intersections with high overall crash numbers, red light running crashes, and/or citations (NHTSA, 2010b). Since RLCs are typically installed at sites with high violation and/or crash frequency instead of random assignment, any reductions in the event analyzed may be due to RTM, that is, data that falls in line with the average results found in the area, regardless of intervention implementation. RTM occurs when unusually high or small numbers of crashes tend to be followed by measurements that are closer to the long term average. Not accounting for RTM may overestimate the benefits of RLCs. Studies which have controlled for RTM have found lower rates of crashes and injuries (Retting \& Kyrychenko, 2002).

Another bias which can occur during an RLC study is spillover. Analyzing the impact of RLCs requires an appropriate selection of control sites. Improper selection can result in underestimating the effect of RLCs due to spillover. This is caused by RLCs influencing a driver's behavior to sites that extend beyond the camera equipped intersections. As a result, the non-equipped sites will also experience a decrease in red light crashes. Although spillover may bring out a positive, area-wide effect, that is, a 
reduction in crashes and injuries for both RLC and nearby non-treatment sites, it is sometimes not accounted for in crash intervention studies. Among the few studies that accounted for spillover, all found some degree (Retting et al., 1999; Retting \& Kyrychenko, 2002; Retting \& Ferguson, 2003). Controlling for spillover effects also resulted in greater reductions of all and right angle crashes as well as reduced increases in rear-end collisions (Shin \& Washington, 2010; Erke, 2009). Despite this evidence, studies which accounted for spillover examined intersections located within small jurisdictions. It is possible that since these cities are small in area, all non-camera sites will be within close proximity to an RLC site, thus increasing the likelihood for spillover. To date, it is unknown whether the effects of RLCs would extend to sites isolated from camerainstalled sites within large metropolitan areas.

\section{Research Objectives}

The objective of this proposal is to assess whether RLCs are effective in improving safety at signalized intersections within Miami-Dade County. Specific objectives include:

Objective 1: Investigate the methodologies used in well-designed RLC studies Objective 2: Investigate which statistical models are most appropriate for RLC studies Objective 3: Determine whether RLCs reduce the rate of injury crashes associated with red light running within Miami-Dade County

\section{Specific Aims}

Aim 1: To determine which methodologies should be employed in a well-designed RLC study by performing a literature review examining previous research. 
Aim 2: To determine the most appropriate statistical model to properly estimate the effectiveness of RLC's.

Aim 3: To determine whether RLC's reduce the incidence of injury crashes within a major metropolitan city while controlling for factors typically not accounted for such as RTM, spillover effects, and an intersection's geometric characteristics. 


\section{References}

1. Centers for Disease Control and Prevention (CDC). WISQARS (Web-based Injury Statistics Query and Reporting System). (2011a). Retrieved from http://www.cdc.gov/injury/wisqars.

2. Centers for Disease Control and Prevention (CDC). (2011b). Vital Signs: Nonfatal, motor vehicle-occupant injuries (2009) and seat belt use (2008) among adults—United States. Morbidity and Mortality Weekly Report, 59(51), 1673-1720.

3. World Health Organization (WHO). (2013). Global status report on road safety 2013. Retrieved from http://www.who.int/violence_injury_prevention/road_safety_status/2013/en/index.html

4. National Highway Traffic Safety Administration National Center for Statistics and Analysis U.S. Department of Transportation (2012). Alcohol Impaired Driving. Report No: DOT HS 811 700. Retrieved from http://www-nrd.nhtsa.dot.gov/Pubs/811700.pdf

5. National Highway Traffic Safety Administration - National Center for Statistics and Analysis, U.S. Department of Transportation. (2010a). Distracted Driving 2009. Report No: DOT HS 811 379. Retrieved from http://www.distraction.gov/research/PDFFiles/Distracted-Driving-2009.pdf

6. Chen HY, Senserrick T, Martiniuk ALC, Ivers IQ, Boufous S, ... Norton R. (2010). Fatal crash trends for Australian young drivers 1997-2007: Geographic and socioeconomic differentials. Journal of Safety Research, 41(2), 123-128.

7. Federal Highway Administration - U.S. Department of Transportation (2014). Safety at Signalized Intersections - Short Version. Retrieved from http://safety.fhwa.dot.gov/intersection/signalized/presentations/sign_int_pps051508/short lindex.cfm.

8. National Highway Traffic Safety Administration - National Center for Statistics and Analysis, U.S. Department of Transportation. (2010b). Crash Factors in IntersectionRelated Crashes: An On-Scene Perspective. Report No: DOT HS 811 366. Retrieved from http://www-nrd.nhtsa.dot.gov/Pubs/811366.pdf

9. National Highway Traffic Safety Administration National Center for Statistics and Analysis U.S. Department of Transportation. (2001). Traffic Safety Facts 2000. A Compilation of Motor Vehicle Crash Data from the Fatality Analysis Reporting System and the General Estimates System. Report No: DOT HS 809 337. Retrieved from wwwnrd.nhtsa.dot.gov/Pubs/TSF2000.pdf 
10. National Highway Traffic Safety Administration National Center for Statistics and Analysis U.S. Department of Transportation (2013). Traffic Safety Facts 2011. A Compilation of Motor Vehicle Crash Data from the Fatality Analysis Reporting System and the General Estimates System. Report No: DOT HS 811 754. Retrieved from http://www-nrd.nhtsa.dot.gov/Pubs/811754AR.pdf

11. Abdel-Aty M.A. \& Radwan E.A. (2000). Modeling traffic accident occurrence and involvement. Accident Analysis and Prevention, 32(5), 633-642.

12. Yan X, Radwam E, Abdel-Aty M. (2005). Characteristics of rear-end accidents at signalized intersections using a multiple logistic regression model. Accident Analysis and Prevention. 37(6), 983-995.

13. Federal Highway Administration (2005). Safety evaluation of red light cameras, an executive summary. Publication No: FHWA-HRT-05-049. Retrieved from http://www.fhwa.dot.gov/publications/research/safety/05049/.

14. Retting R.A, Williams A.F, Preusser D.F, \& Weinstein H.B. (1995). Classifying urban crashes for countermeasure development. Accident Analysis and Prevention, 27(3), 283-294.

15. Retting R.A, Ulmer R.G, \& Williams A.F. (1999). Prevalence and characteristics of red light running crashes in the United States. Accident Analysis and Prevention, 31(6), 283-294.

16. Retting R.A \& Kyrychenko S.Y. (2002). Reductions in injury crashes associated with red light camera enforcement in Oxnard, California. American Journal of Public Health, 92(11), 1822-1825.

17. Retting R.A \& Ferguson S.A. (2003). Effects of red light cameras on violations and crashes: A review of the international literature. Traffic Injury Prevention, 4(1), 17-23.

18. Shin K. \& Washington S. (2007). The impact of red light cameras on safety in Arizona. Accident Analysis and Prevention, 39(6), 1212-1221.

19. Erke, A. (2009). Red light for red-light cameras? A meta-analysis of the effects of red-light cameras on crashes. Accident Analysis and Prevention, 41(5), 897-905.

20. Miaou SP \& Lum H. (1993). Modeling vehicle accidents and highway geometric design relationships. Accident Analysis and Prevention. 25(6), 689-709.

21. Freedman M \& Esterlitz JR (1990). Effects of the 65-mph speed limit on speeds in three states. Transportation Research Record: Journal of the Transportation Research Board, 1281, 52 -61. 
22. Retting RA \& Greene MA (1997). Traffic speeds following the repeal of the national maximum speed limit. ITE Journal, 67, 42-46.

23. Elvik R. (2012). Speed limits, enforcement, and health consequences. Annual Review of Public Health, 33, 225-238.

24. Wang X \& Abdel-Aty M. (2006). Temporal and spatial analyses of rear-end crashes at signalized intersections. Accident Analysis and Prevention. 38(6), 1137-1150.

25. Solomon D. (1964). Accidents on main rural highways related to speed, driver, and vehicle. Washington DC: Federal Highway Administration.

26. Joksch HC (1993). Velocity change and fatality risk in a crash - A rule of thumb. Accident Analysis and Prevention, 25(1), 103-104.

27. Elvik R. (2008). Dimensions of road safety problems and their measurement. Accident Analysis and Prevention, 40(3), 1200-1210.

28. Shiner D. (1998). Speed and crashes: A controversial topic and an elusive relationship. Transportation Research Board Special Report, 254, 221-276.

29. Vernon DD, Cook LJ, Peterson KJ, Dean M. (2004). Effect of repeal of the national maximum speed limit law on occurrence of crashes, injury crashes, and fatal crashes on Utah highways. Accident Analysis and Prevention, 36(2), 223-229.

30. Renski H, Khattak AJ, Council FM. (1999). Effect of speed limit increases on crash injury severity: analysis of single-vehicle crashes on North Carolina Interstate highways. Transport Research Record: Journal of the Transportation Research Board, 1665, 100108.

31. Balkin S \& Ord J. (2001). Assessing the impact of speed-limit increases on fatal interstate crashes. Journal of Transportation and Statistics, 4(1), 1-12.

32. Milton JC \& Mannering FL. (1998). The relationship among highway geometrics, traffic-related elements and motor-vehicle accident frequencies, Transportation 25(4), 395-413.

33. Abdel-Aty M.A. \& Radwan E.A. (2000). Modeling traffic accident occurrence and involvement. Accident Analysis and Prevention, 32(5), 633-642.

34. Noland RB \& Oh L (2004). The effect of infrastructure and demographic change on traffic-related fatalities and crashes: A case study of Illinois County-Level data. Accident Analysis and Prevention, 36(4), 525-532. 
35. Awadzi KD, Classen S, Hall A, Duncan RP, Garvan CW. (2008). Predictors of injury among younger and older adults in fatal motor vehicle crashes. Accident Analysis and Prevention, 40(6), 1804-1810.

36. Council FM \& Stewart JR (2000). Safety Effects of the conversion of rural two-lane to four-lane roadways. ITE Journal, 70(4), 37-42.

37. Yan X, Radwam E, Abdel-Aty M. (2005). Characteristics of rear-end accidents at signalized intersections using a multiple logistic regression model. Accident Analysis and Prevention. 37(6), 983-995.

38. Porter BE \& England KJ. (2000). Predicting red-light running behavior: A traffic safety study in three urban settings. Journal of Safety Research, 31(1), $1-8$.

39. Lord D, Washington S, Ivan J. (2005). Poisson, poisson-gamma, abd zero-inflated regression models of motor vehicle crashes: balancing statistical fit and theory. Accident Analysis and Prevention, 37(1), 35-46.

40. Harwood DW, Council FM, Hauer E, Hughes WE, Vogt A. (2000). Prediction of the expected safety performance of rural two-lane highways. Federal Highway

Administration. Report No: FHWA-RD-99-207.

41. Qin X, Ivan JN, Ravishanker N. (2004). Selecting exposure measures in crash rate prediction for two-lane highway segments. Accident Analysis and Prevention, 36(2), 183191.

42. Hall JW \& Hurtado M. (1992). Effect of intersection congestion on accident rates. Transportation Research Record: Journal of the Transportation Research Board, 1376, $71-77$.

43. Mehta G \& Lou Y (2013). Calibration and development of safety performance functions for Alabama. Transportation Research Record: Journal of the Transportation Research Board, 2398, 75-82.

44. Brimley BK, Saito M, Shultz GG. (2012). Safety performance function development of new models for rural two-lane, two-way highways. Transportation Research Record: Journal of the Transportation Research Board, 2279, 82-89.

45. Greibe P (2003). Accident prediction models for urban roads. Accident Analysis and Prevention, 35(2), 273-285. 


\section{CHAPTER II}

\section{MANUSCRIPT 1 - LITERATURE REVIEW (PUBLISHED)}

Red Light Cameras in the United States - A Systematic Literature Review

Anthoni F Llau Jr. 


\begin{abstract}
Objective: To examine the available scientific evidence based on peer-reviewed publications concerning the effectiveness of Red Light Cameras (RLCs) within the U.S. traffic system.

Methods: Relevant literature published prior to December 2012 was retrieved from the PubMed, Medline, and Engineering index databases using free-text term queries. Jurisdictions with either a fixed number of RLCs studied or area wide programs within the U.S. were included. RLC studies with additional interventions were excluded. Eight RLC studies were extracted and grouped into three categories based on outcome measures: violations, crashes, and injuries/fatalities.
\end{abstract}

Results: All eight studies reviewed showed significant reductions in the frequency/rate of violations, crashes, and injuries at intersections after RLC implementation. RLC interventions appear to decrease violations, crashes, and injuries at intersections. Conclusions: Despite limited peer-reviewed publications available in the literature, RLCs have been shown to decrease violations, crashes, and injuries at intersections. Some studies however, contained methodological shortcomings. Therefore, results should be confirmed with stronger methodological approaches. Although spillover effects appeared to be evident, many of the jurisdictions examined were small in area. Thus, it is unknown whether spillover resulting from RLCs would have similar effects in large metropolitan areas. To determine the full public health impact of RLC programs, crashes, injuries, and fatalities should be considered as primary outcomes of interest. To accomplish this requires a clear definition of which types of crashes will be included for RLC studies. Lastly, it is unknown whether RLCs would be effective in reducing crashes 
resulting from distracted or alcohol impaired drivers. Future studies should examine the effects of RLCs by exclusively analyzing these crash types. 


\section{Introduction}

In the United States, motor vehicle crashes are the leading cause of death among individuals aged $5-34$ years (Centers of Disease Control [CDC] 2011a). Among this age group, 18,266 persons were killed as the result of motor vehicle crashes during 2007, representing $22 \%$ of overall deaths and 55\% of injury-related deaths (CDC 2011b). Motor vehicle occupants comprise the majority of crash victims, accounting for $83 \%$ of all related fatalities, most of which are either car or light truck passengers (National Highway Traffic Safety Administration [NHTSA] 2011a). Crashes also produce an enormous burden not only in terms of injury and lives lost but in cost. During 2005, the cost of crash-related deaths and injuries was estimated to be $\$ 99$ billion (Naumann et al. 2010).

Roads have a major effect on crash risk since their conditions impact how motorists perceive their environment. Road design such as road surface, lane width and street markings can influence a vehicle's speed (Edquist et. al, 2009). Moreover, poorly designed or maintained roads may influence the frequency and severity of motor vehicle crashes (Zaloshjna \& Miller, 2009). Road signs and traffic control signals also provide instructions for road users (i.e. drivers, bicyclists, pedestrians) to limit crashes.

Intersections, however, may pose greater crash risk since at least two roads cross each other and driver actions such as turning left, right, or crossing over have the potential for conflicts. Although intersections represent a very small fraction of the U.S. roadway system, a significantly large proportion of crashes take place at these locations (NHTSA 2010). During 2008, approximately $40 \%$ of U.S. crashes occurred at an intersection, of which over half (52\%) took place at roads with traffic signals (NHTSA 
2010). This indicates an excessive proportion of crashes transpire at signalized intersections considering they constitute only $10 \%$ all intersections within the U.S. (Federal Highway Administration, 2000). Crashes at signalized intersections can result in large numbers of injuries and fatalities. Nearly one-third of traffic signal crashes resulted in at least one occupant injury (NHTSA 2010). Despite national prevention efforts targeting this public health problem, the percentage of fatal crashes occurring at intersections with traffic signals increased 5\% between 2000 and 2009 (NHTSA 2001; NHTSA 2011b). Many crashes at signalized intersections can be attributed to drivers running red lights.

Red light runners account for $22 \%$ of urban collisions and over one-fourth of all injury collisions (Retting et al. 1995). According to the U.S. Department of Transportation, approximately 56\% of Americans acknowledge running a red light (Romano et al. 2005). Recent research has concentrated on the characteristics of drivers who run red lights. Red light runners involved in fatal crashes were slightly more likely to be males under the age of 30 years (Retting et al. 1999). This group may be disproportionately involved in red light running crashes since they tend to drive more recklessly than other gender/age groups (Huang et al. 2008).

Drivers with declining visual ability may also pose a greater risk of running red lights. For example, drivers between the ages of 67 and 87 years who scored poorly in visual attention tests were $10 \%$ more likely to run red lights (West et al. 2010). Older drivers are also prone to being seriously injured due to running red lights. Elderly drivers were $70 \%$ more likely versus all other ages to be severely injured when involved in red light running crashes (Huang et al. 2008). Furthermore, increased frailty due to reduced 
bone mass, osteoporosis, and decreased muscular strength is more likely in older individuals (Nicaj et al. 2006) resulting in greater risks of severe injury following a motor vehicle crash. Nearly three-fourths (72\%) of elderly drivers over age 70 were fatally injured in red light running crashes as compared with $29 \%$ of drivers younger than 20 (Retting et al. 1999).

The prevalence of red light running is also higher among individuals with atypical driving behaviors. Among drivers that had consumed alcohol, the prevalence of red light running was 54\% greater than that of other drivers (Romano et al. 2005). Additionally, lack of seat belt use was more prevalent among red light runners. Other studies have shown that drivers without valid licenses or with prior traffic violations are also more likely to run red lights. Among fatal crashes involving a traffic signal, red light runners were more likely to have either suspended, revoked, or invalid licenses (Retting et al. 1999). In addition, red light runners were also more likely to have at least two traffic violations and previous driving under the influence (DUI) violations. Romano, et al. 2005 , found a high prevalence (72\%) of fatal red light running collisions among drivers with previous DUI convictions.

Several interventions have been proposed to decrease the risk of red light running crashes, including police enforcement, educational campaigns, and engineering modifications such as signal timing changes. Red light cameras (RLCs), however, are increasingly being used to discourage red light runners and decrease related crashes. RLCs have been used internationally since the 1970's, while the first U.S. red light camera program was developed in the early 1990's (Retting et al. 1999). This 
intervention can assist in decreasing red light running by automatically photographing the license plates or drivers of vehicles who run red lights.

Cameras are typically placed in a corner of an intersection and are activated by sensors embedded under the road. When a vehicle enters the magnetic field at a minimum speed during a red light, the camera systems activate and begin recording the incident. Pictures are then taken of the vehicle entering and leaving the intersection, in addition to a zoomed photo of the license plate. Moreover, the camera records the date and time the driver ran the red light. The photograph is subsequently reviewed by an officer and if they determine a violation occurred according to state/local laws, a ticket is usually issued to the owner of the vehicle. In some states, such as California and Colorado, however the driver is liable for paying the citation (Insurance Institute for Highway Safety, 2013). The benefit of this intervention is that police presence is not required. A driver may be more inclined to run a red light if they do not observe any law enforcement present at the intersection. RLCs counter this by helping enforce traffic laws without the presence of police.

Early RLC studies were mixed on whether they were effective. A study conducted in Sydney Australia, examined sixteen red light camera sites matched to sixteen controls based on crash history, traffic volume, and intersection geometric characteristics for two years before and after enforcement (Hillier et al. 1993). Treatment and control sites were grouped according to whether a camera was active for long or short periods of time. A log-linear model was used to examine for any differences in the change of right angle, turning (right/left), rear end, and injury crashes. The authors found a significant reduction in injury crashes, a non-significant decrease in total crashes, while experiencing increases 
in right angle and rear end crashes. The author concluded that cameras should only be placed at sites with a clear history of high crash frequency. A review of this study noted that results may have been influenced by warning signs being placed at all camera intersections (McGee \& Eccles, 2003). It is thought that spillover effect may be more pronounced if warning signs are placed on streets upon entering a jurisdiction with RLCs (McGee \& Eccles, 2003). Moreover, Hillier (1993) stated no clear information was provided regarding the statistical methodology, other than a log-linear model was used.

A study conducted in Adelaide, South Australia examined crash change at eight camera and fourteen similar control sites five years before and after implementation (Mann et al. 1994). Yellow phases at several camera sites were also increased from three to four seconds during the program's introduction. The authors found a slight reduction in overall crashes at camera sites. There was also a significant reduction at those camera sites with additional modifications compared to control sites. The author, however acknowledged that cameras were installed at high risk intersections, thus the treatment and control groups were not comparable and that RTM could have influenced their results and examining a small number of sites likely prevented a statistical detection of small effects (Mann et al. 1994). Moreover, the author could not separate the effect of RLC's at sites with yellow phase increases.

Several studies regarding the lack of effectiveness regarding RLC's have also been released. A study conducted in Greensboro, North Carolina examined 303 intersections, eighteen of which had an RLC installed (Burkey \& Obeng, 2004). Crash data was obtained from January 1999 through September 2003. A regression model was developed adjusting for several variables including speed limit, Average annual daily 
traffic (AADT), number of straight through and left turn lanes, and weather conditions. The authors stated that RLCs were associated with a 42\% increase in overall crashes, a $78 \%$ increase in rear-end crashes, and a nonsignificant $12 \%$ decrease in right-angle crashes. A review of this study was provided by Kyrychenko \& Retting (2004) who stated that this research contained several weaknesses which invalidated conclusions.

One limitation was that the authors' selections of controls, signalized intersections without RLCs, were within the same community. Since publicity generally makes drivers aware a city is using RLCs assigning control sites within the same community is likely to produce underestimates of the benefits associated with red light camera enforcement. Kyrychenko \& Retting also stated that the cameras were increasing crashes due to an erroneous statistical model which failed to account for the fact that RLCs are normally installed in locations with a history of high crashes.

A second study examined the impact of RLCs in six Virginia jurisdictions based on seven years of crash data (January 1998 through December 2004) (Garber et al. 2007). The authors examined 3,500 crashes occurring at 25 sites with RLCs and 48 comparison intersections. Several analytic techniques were implemented including simple beforeafter comparisons and Empirical Bayes approaches. Results varied depending on the type of crash, jurisdiction, and analysis employed. The authors found an increase in rear-end crashes and decreases in red light running crashes. They also found significant variation in the change in crashes by intersection and jurisdiction.

A subsequent review of this paper also found several flaws with the methodology employed (Persaud et al. 2008) who noted that the only effective analytic technique used was the Empirical Bayes method, since this model exclusively accounts for regression to 
the mean (RTM) and changes in factors such as traffic volume, weather, and driving habits. Several of the Empirical Bayes models applied were erroneous since the process used to predict the expected number of crashes at the enforced intersections if no camera was present was likely underestimated. Issues with the models included large numbers of potentially correlated independent variables and small sample crash sizes, producing unstable and unreliable parameter estimates. Additionally, the mean number of crashes at the camera sites for all six jurisdictions during the pre-enforcement period was substantially higher than comparison intersections, biasing the crash effect estimates. Third, comparison sites were located within the jurisdictions with RLCs. Lastly, there were large fluctuations in traffic volumes at some intersections for consecutive years. The reviewers concluded the Garber study should not be used as guidance to communities considering RLC use (Persaud et al., 2008).

A literature review conducted in 2003 examined several RLC studies conducted internationally including some previously discussed (Sydney and Adelaide, Australia). Findings indicated red light camera enforcement generally reduced violations by 40 $50 \%$ and injury-related crashes by $25-30 \%$ (Retting et al. 2003). Although Retting's review provided valuable information, the majority of these older studies contained several limitations and were not published in peer-reviewed scientific journals, where methods and analyses are heavily scrutinized to meet a high standard of quality and validity. Furthermore, several of the reports examined took place outside the United States, where traffic laws, driving behaviors, road sign terminology, vehicle safety standards, and road design can vary greatly (Spicer et al. 2005; World Health Organization 2009). The purpose of this current review is to examine the available 
scientific evidence pertaining to the effectiveness of RLCs within the United States traffic system, based on more recent peer-reviewed publications.

\section{Methods}

\section{Search Strategy}

During January 2013, studies pertaining to RLCs were retrieved from the PubMed, Medline, and Engineering Index (Compendex) electronic databases. The following free-text terms were used in "All fields" to search for relevant articles: "red light camera*”, "red-light camera*”, "red light runn*”, "red-light runn*”, "red light crash*", "red-light crash*, "red light inj*”, "red-light inj*”, "red light viol*”, and "redlight viol*”.

\section{Study Selection and Outcome Measures}

The search was limited to articles published prior to December 31, 2012.

Jurisdictions with either a fixed number of RLCs studied or area-wide programs within the United States were included. In order to be selected, studies had to provide results related to any of the following primary outcome variables being measured: a) Red Light Running Violations; b) Motor Vehicle Crashes; or c) Crash Injuries/Fatalities. In order for the intervention to be effective, a significant reduction after camera implementation was needed for any of the three aforementioned outcomes. Red light camera studies with additional interventions (e.g. change in yellow light timings or other engineering modifications) were excluded. Other exclusion criteria included whether cameras detected, in addition to red light running, driving speed. None of the studies examined cameras that ticketed both red light runners and speeding drivers. 


\section{Results}

\section{Studies with Violations as Primary Outcome Variable}

Despite RLCs being used in the U.S. since the 1990's, only a small number of studies using violations as the primary outcome variable have been published. Table 1 lists four evaluations pertaining to the effects of RLCs on signal violations in following locations: (Virginia Beach, Virginia; Fairfax, Virginia; Oxnard, California; and Jefferson Parrish, Louisiana). All four studies indicated a significant reduction in violation rates for red light camera sites, ranging from $40-94 \%$. Similarly, non-camera intersections also experienced $26-50 \%$ reductions in violations, indicating spillover effects.

All four studies employed a before-after design, examining violation rates at intersections prior to and after implementation of RLCs, three of which used control sites for comparison. The largest declines were experienced in Virginia Beach where two of three RLC sites displayed a $100 \%$ reduction in violation rates from baseline levels. The smallest declines were observed in Fairfax and Oxnard, each experiencing a $40 \%$ average reduction in violation rates. One study (Wahl et al. 2010), which examined only one intersection within Jefferson Parrish and no comparison sites, found an $85 \%$ significant decline in the number of weekly violations between the warning period (September and October, 2007) and June 2008 with the steepest decreases occurring the first four months of enforcement.

Despite the evidence suggesting benefits of red light camera utilization, several matters should be addressed. The majority of studies examined sites with RLC installation based on high violation, crash, or crash-related injury history. The Jefferson 
Parrish site was considered one of the 10 most dangerous intersections in the U.S. (Wahl et al. 2010).

Only one jurisdiction (Martinez et al. 2006) employed additional measures to select intersections for RLC implementation (daily traffic volume and plans for engineering modifications). According to the NHTSA (2010), administrative criteria for the implementation of RLCs include: 1) At historically dangerous intersections based on overall crash numbers, red light running crashes, and/or citation data; 2) At intersections where engineering studies concluded that road improvements, driver education initiatives, or other countermeasures cannot be implemented or would not reduce the number of crashes related to red light running; and 3) Suggestions from law enforcement and traffic safety professionals as well as input from community groups including citizen complaints regarding red light running. Since RLCs are typically installed at sites with the highest number of violations and/or crashes instead of random assignment, any reductions in the event analyzed could simply be due to RTM, that is data that falls in line with the average results found in the area, even with or without any intervention implementation. As previously concluded by Retting (2003) failure to account for RTM, may overestimate the benefits of RLCs. There are several ways to account for this weakness, including randomly selecting RLC and control sites or employing Bayesian analysis, however none of the four studies employed these methods.

Three studies addressed for potential spillover effects (Table 1), which are caused by red-light cameras influencing a driver's behavior to extend to sites beyond the cameraequipped intersections. Consequently, the non-equipped sites experience a decline in red light crashes, resulting in an underestimate of the benefits of RLCs. Spillover effects 
were addressed by selecting both 1) non-camera sites within the same city enforcing RLCs and 2) sites in jurisdictions without an RLC program. Retting et al. (1999a) examined five intersections with RLCs in Fairfax City. Two additional intersections in Fairfax without RLCs were selected to examine for potential spillover effects. In Oxnard, California, Retting et al. (1999b) examined nine sites with RLCs and three non-camera sites within city limits. In addition, both studies examined violation rates at signalized intersections located in other jurisdictions without an RLC program to assess whether drivers were more likely to commit violations in areas without camera enforcement. Results indicated a large spillover effect within both areas. In Fairfax City, the noncamera intersections experienced a 14 and 34\% reduction in violation rates three months and one year after enforcement, respectively. During the same time period, the intersections outside of Fairfax showed no change in violation rates neither at 3 months nor 1 year. Similarly, violation rates at non-camera sites within Oxnard declined 50\% four months after enforcement, while control sites beyond city limits only showed a $4 \%$ reduction. Comparisons of three camera and three non-camera sites within Virginia Beach found no significant differences in red light running odds. In addition, red light running was 1.95 times as likely to occur at two control sites located outside of Virginia Beach, thus suggesting a spillover effect as well.

Data collection duration also varied for each study, ranging from three months to one year. Two (Retting et al. 1999a; Retting et al. 1999b) compared violation rates prior to and three months after RLC enforcement, however results were inconclusive. One measured violation rates in Fairfax at camera and non-camera sites three months and one year after enforcement (Retting et al. 1999a). Results suggested that violation rates did 
not significantly decline after three months, however a significant decrease was shown after one year. In contrast, violation rates in Oxnard significantly declined $42 \%$ for camera versus non-camera sites three months after enforcement (Retting et al, 1999b). Lastly, representation bias was also possible for some studies. For example, Martinez (2006) examined three camera and three non-camera sites within Virginia City and two control sites in a second city. Observations were recorded for five phases during an eight month period. Each observation phase was from 4:00 - 6:00 pm for approximately 10 14 days. Although results indicated red light running was 1.95 times as likely for the control versus camera sites, all observations were recorded during rush hour traffic, thus results may not have been representative of regular driving patterns.

\section{Studies with Motor Vehicle Crashes as Primary Outcome Variable}

A small number of publications exist pertaining to the impact of motor vehicle crashes from red light camera installation. Table 2 lists studies comparing crash data before and after RLC installation. Although each showed little change in the overall number of crashes, all reported significant reductions in right angle and red light running crashes, which are typically associated with greater injury severity. In contrast, rear end crashes increased or were unchanged at camera sites.

Two studies employed Bayesian analysis to control for RTM. In Arizona, Shin and Washington (2007) examined the impact of RLCs to reduce crashes on 24 intersections in Scottsdale and Phoenix, Arizona. In Scottsdale, a simple before-after methodology was designed using Empirical Bayes analysis, while in Phoenix a beforeafter study with comparison group was used. Bayesian analysis was not employed for the Phoenix comparison. In Scottsdale, the authors found, 1) a non-significant $20 \%$ decline in 
right angle crashes, 2) a significant $45 \%$ decrease in left turn crashes, and 3) a significant $41 \%$ increase in rear-end collisions. In Phoenix, right angle crashes declined by $42 \%$ while rear-end crashes increased by $20 \%$, both of which were significant. No change in total crashes was evident for either city.

Hallmark et al. (2010) employed a Bayesian analysis to compare crash incidence at four intersections with RLCs to five control sites in Davenport, Iowa. Control sites were similar to red light camera intersections with respect to traffic volume and crash frequencies. Crashes were then further divided as red light running/rear-end and separately analyzed. The authors found a barely significant $20 \%$ decline in the rate of total collisions at red light camera intersections (95\% CI: $0.01-1.97)$ and a $40 \%$ reduction in red light running crash rates $(95 \% \mathrm{CI}$ : $0.06-1.4)$ for the camera sites. No difference in red light running crashes was observed for the control intersections. Lastly, no change in rear-end crashes was evident for either the treatment or control sites.

A third evaluation conducted in Texas assessed the crash frequency of 275 intersections with RLCs in 38 communities. Crash records were analyzed for one, two, and three year periods immediately prior to and after RLC activation. Crashes were grouped into two types - red light and non-red light related. Overall, right-angle, rearend, and other crashes were compared by crash type prior to and after camera activation for each time period. Results indicated that overall crashes attributed to red light running declined $10 \%$ after one year and $21 \%$ after three years. In contrast, non-red light related crashes increased $4 \%$ after one year and declined $8 \%$ after three years. Right-angle crashes attributed to red light running declined by $19 \%$ after one year and $26 \%$ after three years. Non-red light running right angle crashes experienced little change after one year 
and declined by $9 \%$ after three years. Rear-end collisions attributed to red light running (defined by the authors as a lead vehicle which braked suddenly for a yellow signal and a trailing vehicle struck the lead vehicle from behind) doubled for one, two, and three years after camera activation. In contrast, non-red light running rear end crashes experienced little change after three years. In this study, RTM may not have been a factor since large numbers of intersections were measured during several time periods. Reductions in RTM can occur by increasing the number of measurements since it reduces the variability of the subject being assessed (Barnett et al. 2005).

Although RTM was generally accounted for, all were unable to control for spillover effects despite evidence pointing to its presence. In Arizona, the authors observed a spillover effect within Scottsdale, however, they did not control for this bias (Shin 2002). Similarly, Persaud (2005) detected a modest spillover effect in right angle crashes at untreated sites. Lastly, control sites within Davenport were within close proximity to the RLC intersections (Hallmark 2010). By not selecting adequate control sites for comparison, the effect of crashes from red light camera installation may have been underestimated. It is believed that in order to fully control for spillover effects, control sites should be situated away from the jurisdiction enforcing RLC's as well as its associated publicity (McGee and Eccles 2003).

Another methodological complication lies in how crashes should be defined, which were not consistent for each study. For example, left turn crashes were examined in Arizona but excluded in Davenport. If all left turn crashes are classified as red light running, it may produce an overestimate in the frequency of collisions since some involve vehicles where one driver turns left during an unprotected green light, while a second is 
traveling straight on the opposite roadway amidst a green light cycle. Inclusion of other crash types for analysis was also conflicting. In Arizona, crashes resulting from the physical condition of drivers (i.e. under the influence, distraction), were excluded. In contrast, no such exclusion was specified in the Davenport study.

\section{Studies with Injury Crashes as Primary Outcome Variable}

Table 3 identifies only two published studies which analyzed injury crashes as a primary outcome, however, the authors were able to control for both regression to the mean and spillover effect (Retting and Kyrychenko, 2002). They compared the change in injury-related crashes for signalized and non-signalized intersections in Oxnard to Bakersfield, San Bernardino, and Santa Barbara. All four California cities were similar with respect to population and crashes. Within Oxnard, RLCs were installed in one approach at eleven signalized intersections. The other three cities, which did not have cameras, were used as control sites to establish that any crash decreases in Oxnard were due to the camera program. Crash data for both signalized and non-signalized intersections in Oxnard and the three control cities were compared for 29 months for both before and after camera installation. Crash data for each of the eleven camera-equipped intersections in Oxnard were aggregated for analysis. It was assumed that whatever effect cameras had on crash occurrence at the camera-equipped intersections would spill over to other signalized intersections within Oxnard. Previous studies conducted in Oxnard and Fairfax provided support to this assumption (Retting 1999a \& Retting 1999b). A loglinear regression model was developed to assess changes in crash occurrences, injury crashes, and crash types (right-angle and rear-end) in Oxnard and the three control cities after enforcement. 
Results showed red light camera enforcement significantly decreased the number of overall crashes at all signalized and unsignalized intersections in Oxnard by $7 \%$ and the number of injury crashes by $29 \%$. In addition, Oxnard experienced a $32 \%$ decrease in right-angle crashes and $68 \%$ reduction in right-angle injury crashes. Both of these reductions were significant. No difference in rear-end crashes was found. One note of importance was that during the study, the fine for red light running violations had considerably increased from $\$ 104$ to $\$ 271$. As a result, the increase may have been an additional factor in drivers avoiding red light running. An additional limitation of this study was the possibility of one site accounting for a large portion of the overall decrease, which may be more likely when examining small numbers of sites.

A second evaluation examined RLC safety across seven U.S. jurisdictions (Persaud et al. 2005). Their approach sought to overcome limitations of previous RLC evaluations by accounting for regression to the mean, normalizing for traffic volume differences during before and after periods, merging data across jurisdictions to provide a larger sample size, and controlling for spillover effects. Red light running-related crashes were classified as right-angle or rear-end. Right angle and rear-end crashes were included if occurring within 20 and 150 feet of an intersection, respectively. Injury collisions were defined as crashes with at least one fatality or definite injury. A large number of sites were used in the analysis including 132 RLC, 408 untreated signalized, and 296 unsignalized comparison intersections across the seven jurisdictions. Information was obtained regarding several variables including traffic volumes, intersection geometrical characteristics, other treatments applied during study period, and advance warning signage. An Empirical Bayes analysis was performed to assess whether red light running 
crash (overall and injury only) incidence decreased at the treatment sites. Untreated signalized and unsignalized intersections were used to calibrate the safety performance function (SPF), which is a statistical model used to estimate average crash frequencies for a specific site type based on traffic volume and other characteristics. A thorough description of Empirical Bayes analysis and development of SPF's can be found in Hauer (1997). Crash incidence was aggregated across all seven jurisdictions. The authors found a significant decrease in total and injury right angle crashes and a significant increase in rear-end crashes (Table 2). The direction of these effects were relatively consistent across each jurisdiction. Although results were consistent with other RLC studies, effects were lower, likely due to controlling for RTM. Although spillover was observed in the reference sites, the authors noted that other treatments at these sites may have occurred and thus influenced crash incidence. The authors also noted that RLC systems would provide a greater benefit if placed in sites with numerous right angle and few rear-end crashes, however, additional studies may be needed to further suggest this.

Retting and Kyrychenko's study period was 29 months, the longest presented in this review. RLC studies with longer durations is another approach to account for RTM, however, one must be vigilant for any engineering changes at a site. Even minor intersection changes made during a study such as increasing the yellow light timings or placing advance warning signs to make drivers aware of RLCs, could render any comparisons invalid. 


\section{Discussion}

Despite the use of RLCs in the U.S. over the past two decades, this literature review encountered only nine articles published in scientific journals regarding their effectiveness. Since the majority of these findings contained methodological shortcomings, a greater number of studies are needed to strengthen the conclusion that

RLCs in the U.S. reduces crashes and related injuries. It is possible that some publication bias may have occurred since "positive" results were more likely to be published and thus included in this review. Including unpublished studies, however, could also bias results by introducing research methodologies that are atypical to those presented. Unpublished studies not only result from obtainment of non-significant findings, but from major methodological or measurement data flaws as well. Searches for unpublished studies may increase the possibility for selection bias (Ferguson 2012). In reviewing both published and unpublished RLC studies, Retting (2003) stated that results varied considerably partially due to the methodological weakness of the studies.

Since only two studies examined RLCs with advance warning signs (Retting 2002 \& Persaud 2005), it is unknown whether they played a factor on results. Many communities may erect advance warning signs at camera-equipped intersections to warn motorists of camera enforcement. It is unknown whether these signs would affect a driver's behavior when approaching a camera-equipped intersection, therefore additional studies may be required to determine its effect.

\section{Gaps/Future Studies}

An important factor that may influence red light running is an intersection's environmental characteristics. Intersection designs can be comprised of its geometric 
attributes (number of lanes, cross intersection) or traffic control features (speed limit). Although several studies have examined the relationship between the street design and number of traffic collision occurrences at intersections, (Abdel-Aty 2005, Bonneson 2004, Wang 2008, and Papaioannou 2007) none have assessed which locations may benefit the most from camera installation to reduce injuries associated with red light running. Since red light running is a leading cause of traffic collision-related injuries at signalized intersections, examining the impact of cameras on changes in injuries and reviewing the environmental characteristics can provide a foundation to better understand the impact of injury reduction through camera installation and its corresponding intersection design.

Although spillover effects may bring out a positive, area-wide effect, that is, a reduction in crashes and injuries for both RLC and nearby non-treatment sites, it is sometimes not accounted for in crash intervention studies. Among the few studies that were able to adequately do so, all found some degree of spillover (Retting 1999b; Retting 2002; and Retting 2003). It must be noted though that some RLCs examined were located within small jurisdictions. For example, Oxnard and Fairfax City have a land area of 27 and 6 square miles, respectively (U.S. Census Bureau, 2012). It is possible that since these cities are small in area, all non-camera sites will be within close proximity to an RLC site, thus increasing the likelihood for spillover effects. To date, it is unknown whether the effects of RLCs would extend to sites isolated from camera-installed sites within large metropolitan areas. To better understand spillover effects, subsequent research could select control sites located at a minimum distance from RLC intersections. 
Violations have been generally used as the primary variable of interest to ascertain the effectiveness of RLC studies, nevertheless to determine the full public health impact of RLC programs, injuries and fatalities should be used as the primary variable of interest. To our knowledge, only two published studies have investigated the effect of RLCs on injury crashes, however, they effectively controlled for both regression to the mean and spillover effects (Retting \& Kyrychenko 2002; Persaud et al. 2005). Findings indicated a significant reduction in overall and right-angle injury crashes which are mostly associated with red light running violations (Retting 2002). Despite this finding, the change in level of injury (i.e. fatalities, major/minor injury) associated from red light running before and after camera installation was not examined. To fully ascertain the effectiveness of RLCs subsequent studies should examine the change in frequency and types of injuries after camera installation, while at the same time accounting for RTM and spillover, especially within larger cities. The effects of RLCs may differ between large and small cities since denser populations can result in lower travelling speeds and consequently fewer severe injuries and fatalities. Determining whether differences exist between large and small cities in the effects of RLCs on fatalities and severe injuries would enhance the existing research regarding RLCs.

Classifying which types of crashes will be included for RLC studies need to be more clearly defined. All studies mentioned in this review applied different inclusion and exclusion criteria for crashes. When deciding crash criteria for an RLC study, certain collisions should be excluded such as those occurring when a driver turns left on an unprotected green light with oncoming traffic. The literature also does not have a clear distinction whether crashes involving distracted/impaired drivers should be included in 
RLC studies. It is unknown whether RLCs would reduce crashes resulting from distracted and alcohol impaired drivers, thus future studies could examine the effects of RLCs for these types of crashes alone. 


\section{References}

Abdel-Aty, M., Yan, X. \& Radwan, E. Characteristics of rear-end collisions at signalized intersections using multiple logistics model. Accident Analysis and Prevention. 2005; 37(6):983-995.

Barnett AG, van der Pols JC, \& Dobson AJ. Regression to the mean: what it is and how to deal with it. International Journal of Epidemiology. 2005; 34(1):215-220.

Bonneson, J. \& Zimmerman, K. Effect of yellow-interval timing on the frequency of red light violations at urban intersections. Transportation Research Board, Washington, DC. 2004; 1865:20-27.

Burkey M. \& Obeng K. (2004). A detailed investigation of crash risk reduction resulting from red light cameras in small urban areas. Greensboro, NC: North Carolina Agricultural and Technical State University. Available at: http://www.ncat.edu/ traninst/Burkey Obeng_Updated Report 2004.pdf. Accessed April 17, 2013.

Centers for Disease Control and Prevention (CDC). WISQARS (Web-based Injury Statistics Query and Reporting System). 2011a. Available at: http://www.cdc.gov/injury/wisqars. Accessed August 28, 2012

CDC. Vital Signs: Nonfatal, motor vehicle-occupant injuries and seat belt use among adults - United States. 2011b. Morbidity and Mortality Weekly Report. 59(51):1673-1720.

Edquist J, Rudin-Brown C, Lenne MG. (2009). Road design factors and their interactions with speed and speed limits. Monash University Accident Research Centre. ISBN 0732623865. ISSN 1835-4815. Report \#298.

Federal Highway Administration. Safety at Signalized Intersections (Short Version). 2010. Available at http://safety.fhwa.dot.gov/intersection/signalized/presentations/sign int pps0515 08/short/). Accessed August 5 ${ }^{\text {th }}, 2013$.

Ferguson, C. J., \& Brannick, M.T. Publication bias in psychological science: Prevalence, methods for identifying and controlling and implications for the use of metaanalyses. Psychological Methods. 2012; 17(1): 120-128.

Garber, NJ, Miller, JS, Abel, RE, Eslambolchi, S, Korukonda, SK. (2007). The impact of red light cameras (photo-red enforcement) on crashes in Virginia. Report no. VTRC 07-R2. Charlottesville, VA: Virginia Transportation Research Council. Available at: http://www.virginiadot.org/vtrc/main/online_reports/pdf/07-r2.pdf. Accessed April 17, 2013. 
Hallmark S, Orellana M, McDonald T, Fitzsimmons E, Matulac. Red light running in Iowa: Automated enforcement program evaluation with Bayesian analysis. Transportation Research Record. 2010; 2182:48-54.

Hauer E. (1997). Observational Before-after Studies in Road Safety: Estimating the Effect of Highway and Traffic Engineering Measures on Road Safety. Pergamon, Elsevier Science Ltd., Oxford, United Kingdom

Hillier W, Ronczka J, Schnerring F. (1993). An evaluation of red light cameras in Sydney. Research Note 1/93, Road Safety Bureau, Roads and Traffic Authority, New South Wales, Australia.

Huang H, Chin H.C, \& Mazharul, H. Severity of driver injury and vehicle damage in traffic crashes at intersections: A Bayesian hierarchical analysis. Accident Analysis and Prevention. 2008; 40 (1):45-54.

Insurance Institute for Highway Safety (2013). Automated Enforcement Laws. Available at http://www.iihs.org/laws/automated enforcement.aspx. Accessed April 17, 2013.

Kyrychenko SY. \& Retting RA. (2004). Review of "A Detailed Investigation of Crash Risk Reduction Resulting from Red Light Cameras in Small Urban Areas" by M. Burkey and K. Obeng. Insurance Institute for Highway Safety. Available at: http://www.iihs.org/research/topics/pdf/r1034.pdf. Accessed April 17, 2013.

Mann T, Brown S, Coxon C. (1994). Evaluation of the effects of installing red light cameras at selected Adelaide Intersections. Report Series 7/97, Office of Road Safety, South Australian Department of Transport, Walkerville, South Australia.

McGee HW, Eccles KA. The impact of red-light camera enforcement on crash experience. A synthesis of highway practice. 2003. Available at:http://www.nhtsa.gov/DOT/NHTSA/Traffic\%20Injury\%20Control/Articles/As sociated\%20Files/HS810763.pdf. Accessed December 10, 2012.

Martinez, KL, Porter, BE. Characterizing red light runners following implementation of a photo enforcement program. Accident Analysis and Prevention. 2006; 38(5):86270 .

National Highway Traffic Safety Administration. U.S. Department of Transportation. (2011a). 2010 Motor Vehicle Crashes, an Overview. Available at: http://wwwnrd.nhtsa.dot.gov/Pubs/811552.pdf. Accessed September 10, 2012. 
National Highway Traffic Safety Administration National Center for Statistics and Analysis, U.S. Department of Transportation. (2011b). Traffic Safety Facts 2009. A Compilation of Motor Vehicle Crash Data from the Fatality Analysis Reporting System and the General Estimates System. Available at: http://wwwnrd.nhtsa.dot.gov/pubs/811402ee.pdf. Accessed August 24, 2012.

National Highway Traffic Safety Administration, National Center for Statistics and Analysis, US Department of Transportation. 2001. Traffic Safety Facts 2000. A Compilation of Motor Vehicle Crash Data from the Fatality Analysis Reporting System and the General Estimates System. Available at: www.nrd.nhtsa.dot.gov/Pubs/TSF2000.pdf. Accessed September 13, 2012

National Highway Traffic Safety Administration. Mathematical Analysis Division, National Center for Statistics and Analysis. Crash Factors in Intersection-Related Crashes: An On-Scene Perspective. 2010; Report Number DOT HS 811366.

Naumann RB, Dellinger AM, Zaloshnja E, Lawrence BA, \& Miller TR. Incidence and total lifetime costs of motor vehicle-related fatal and nonfatal injury by road user type, United States, 2005. Traffic Injury Prevention. 2010; 11(4):353-60.

Nicaj L, Wilt S, \& Henning K. Motor vehicle crash pedestrian deaths in New York City: the plight of the older pedestrian. Journal of Injury Prevention. 2006; 12(6):414416.

Papaioannou P. Driver behaviors, dilemma zone and safety effects at urban signalized intersections in Greece. Accident Analysis \& Prevention. 2007; 39(1):147-158.

Persaud B, Council FM, Lyon C, Eccles K, Griffith M. (2005). Multijurisdictional Safety Evaluation of Red Light Cameras. Transportation Research Record: Journal of the Transportation Research Board. Vol 1922:29-37.

Persaud BN, Retting RA, Lyon C, McCartt AT. (2008). Review of "The Impact of Red Light Cameras (Photo-Red Enforcement) on Crashes in Virginia" by Nicholas J. Garber, John S. Miller, R. Elizabeth Abel, Saeed Eslambolchi, and Santhosh K. Korukonda. Insurance Institute for Highway Safety. Available at: http://www.iihs.org/research/topics/pdf/r1100.pdf. Accessed April 17, 2013.

Retting RA, Williams AF, Preusser DF, \& Weinstein HB. Classifying urban crashes for countermeasure development. Accident Analysis and Prevention. 1995; 27(3):283-294.

Retting RA, Ulmer RG, \& Williams AF. Prevalence and characteristics of red light running crashes in the United States. Accident Analysis and Prevention. 1999; 31(6):687-694. 
Retting RA, Williams AF, Farmer CM, \& Feldman AF. Evaluation of red light camera enforcement in Fairfax, Virginia. Institute of Transportation Engineers. 1999a; 69(8):30-34.

Retting RA, Williams AF, Farmer CM, \& Feldman AF. Evaluation of red light camera enforcement in Oxnard, California. Accident Analysis and Prevention. 1999b; 31(3):169-174.

Retting RA \& Kyrychenko SY. Reductions in injury crashes associated with red light camera enforcement in Oxnard, California. American Journal of Public Health. 2002; 92(11):1822-1825.

Retting RA, Ferguson, SA, \& Hakkert, AS. Effects of red light cameras on violations and crashes: A review of the international literature. Traffic Injury Prevention. 2003; $4(1): 17-23$.

Romano E, Tippens S, \& Voas R. Fatal Red Light Crashes: The Role of Race and Ethnicity. Accident Analysis and Prevention. 2005; 37(3):453-460.

Shin K. \& Washington S. The impact of red light cameras on safety in Arizona. Accident Analysis and Prevention. 2007; 39(6):1212-1221.

Spicer R, Miller T, Langley J, \& Stephenson, S. Comparison of injury case fatality rates in the United States and New Zealand. Injury Prevention. 2005; 11(2):71-76.

United States Census Bureau. State and County QuickFacts. 2012. Available at: http://quickfacts.census.gov/qfd/index.html. Accessed November 21, 2012.

Wahl GM, Islam T, Gardner B, Marr AB, Hunt JP, McSwain NE, Baker CC, Duchesne J. Red light cameras: do they change driver behavior and reduce accidents? J Trauma. 2010; 68(3):515-518.

Walden T. \& Bochner B. Effectiveness of red light cameras - Texas Statewide Evaluation. ITE Journal. 2011; 81:30 - 33.

Wang, X. \& Abdel-Aty, M. Modeling left-turn crash occurrence at signalized at signalized intersections by conflicting patterns. Accident Analysis and Prevention. 2008; 40(1):76-88.

West SK, Hahn DV, Baldwin KC, Duncan DD, Munoz BE, Turano KA, . . BandeenRoche, K. Older drivers and failure to stop at red lights. Journal of Gerontology. 2010; 65(2):179-183. 
Geneva, World Health Organization (2009). Global status report on road safety: time for action. Available at:

http://www.who.int/violence injury prevention/road safety_status/2009. Accessed December 15, 2012.

Zaloshnja E. \& Miller TR. Cost of crashes related to road conditions, United States, 2006. Annals of Advances in Automotive Medicine/Annual Scientific Conference. 2009; 53:141-153. 
Figures and Tables

Table 1.1 Manuscript 1:

U.S. studies of effects of red light cameras on violations

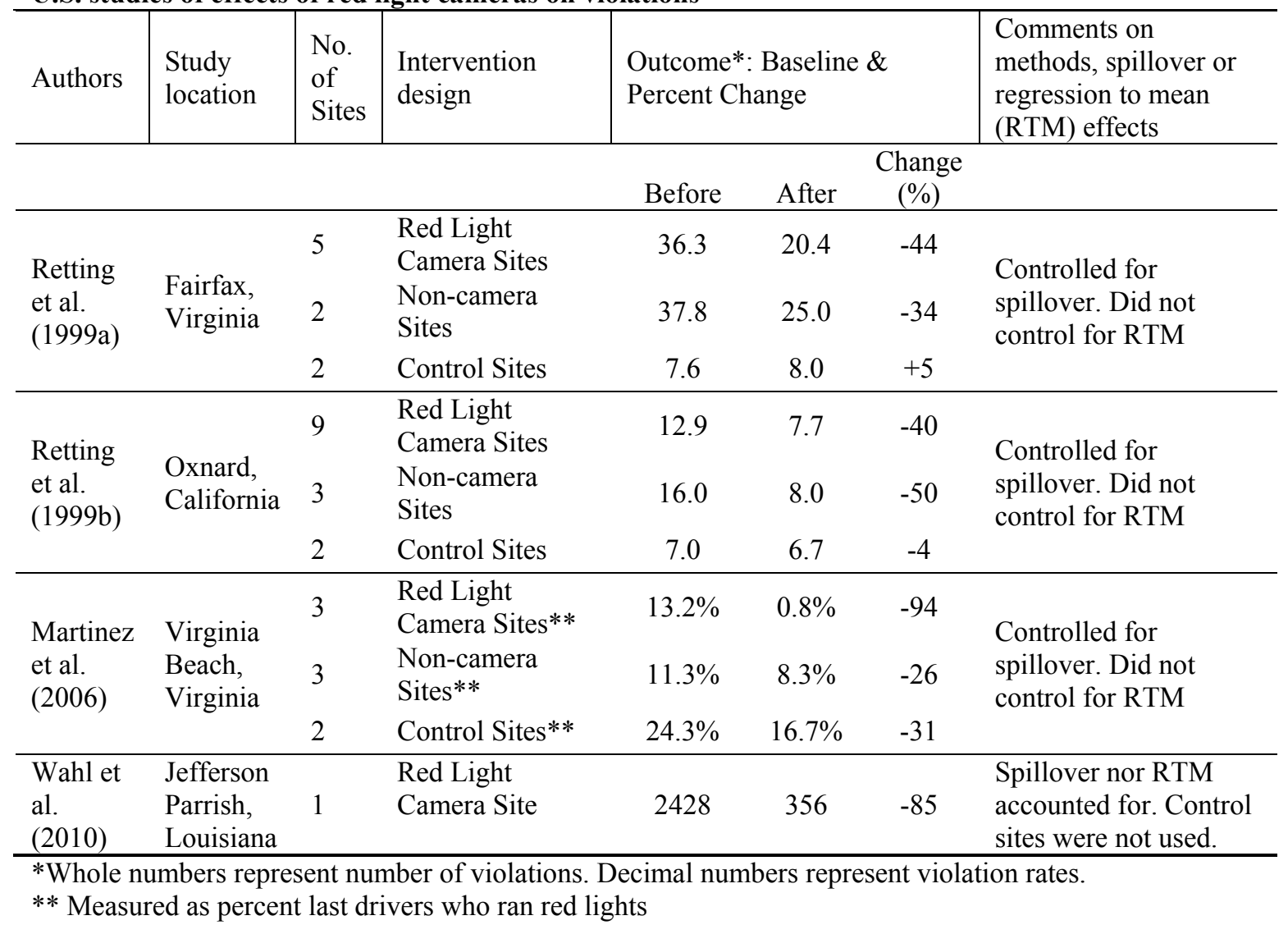


Table 1.2 Manuscript 1:

U.S. studies of effects of red light cameras on crashes

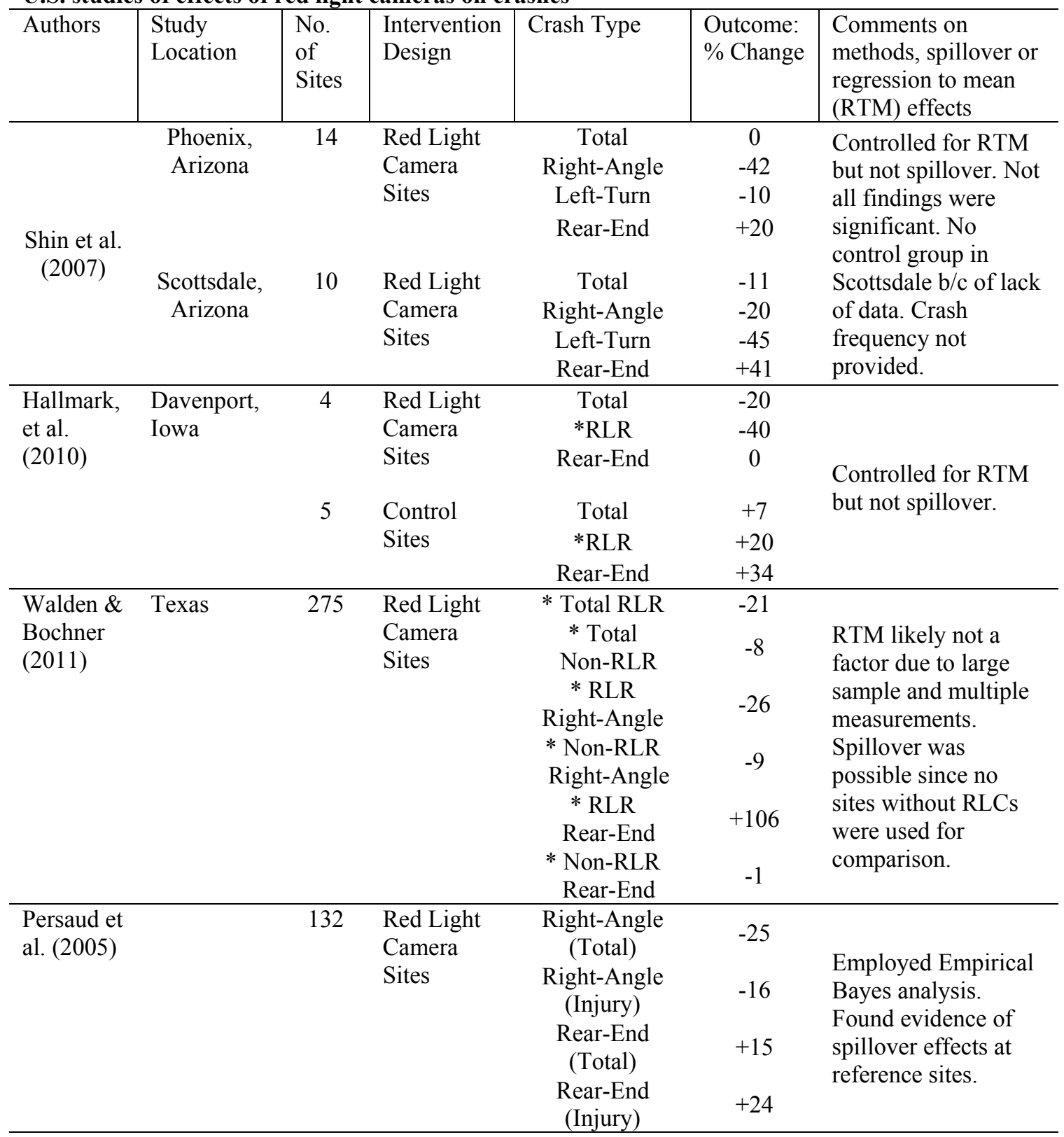

RLR - Red Light Running

$(*)$ - \% Change 3 years after RLR activation 
Table 1.3 Manuscript 1:

U.S. studies of effects of red light cameras on injuries

\begin{tabular}{|c|c|c|c|c|c|c|}
\hline Authors & Study location & $\begin{array}{l}\text { Intersection } \\
\text { Type }\end{array}$ & $\begin{array}{l}\text { Injury } \\
\text { Crashes } \\
\text { (Before) }\end{array}$ & $\begin{array}{l}\text { Injury } \\
\text { Crashes } \\
\text { (After) }\end{array}$ & $\%$ Change & Comments \\
\hline \multirow{8}{*}{$\begin{array}{l}\text { Retting et } \\
\text { al. (2002) }\end{array}$} & Oxnard, California & $\begin{array}{l}\text { Signalized } \\
\text { Intersections }\end{array}$ & 299 & 239 & -20.1 & \multirow{8}{*}{$\begin{array}{l}\text { Controlled for } \\
\text { both spillover } \\
\text { and RTM. }\end{array}$} \\
\hline & & $\begin{array}{l}\text { Non-Signalized } \\
\text { Intersections }\end{array}$ & 173 & 194 & +12.1 & \\
\hline & $\begin{array}{l}\text { San Bernandino, } \\
\text { California }\end{array}$ & $\begin{array}{l}\text { Signalized } \\
\text { Intersections }\end{array}$ & 239 & 246 & +2.9 & \\
\hline & & $\begin{array}{l}\text { Non-Signalized } \\
\text { Intersections }\end{array}$ & 204 & 225 & +10.3 & \\
\hline & $\begin{array}{l}\text { Santa Barbara, } \\
\text { California }\end{array}$ & $\begin{array}{l}\text { Signalized } \\
\text { Intersections }\end{array}$ & 89 & 84 & -5.6 & \\
\hline & \multirow{3}{*}{$\begin{array}{l}\text { Bakersfield, } \\
\text { California }\end{array}$} & $\begin{array}{l}\text { Non-Signalized } \\
\text { Intersections }\end{array}$ & 113 & 115 & +1.8 & \\
\hline & & $\begin{array}{l}\text { Signalized } \\
\text { Intersections }\end{array}$ & 243 & 233 & -4.1 & \\
\hline & & $\begin{array}{l}\text { Non-Signalized } \\
\text { Intersections }\end{array}$ & 245 & 241 & -1.6 & \\
\hline
\end{tabular}




\section{CHAPTER III}

MANUSCRIPT 2 - STATISICAL METHODOLOGY (PUBLICATION ACCEPTED)

IDENTIFICATION OF AN ACCIDENT PREDICTION MODEL FOR RED LIGHT CAMERA ANALYSES 


\title{
MANUSCRIPT 2
}

\section{Identification of an accident prediction model for red light camera analyses}

\begin{abstract}
Objectives: Determining whether red light cameras (RLC's) are effective is difficult for several reasons. One issue is the phenomenon known as regression to the mean (RTM). If not accounted for, results may be biased in estimating the benefit of RLCs. Empirical Bayes (EB) analyses allow researchers to account for RTM by estimating the number of collisions based on crash counts prior to RLC installation at treatment and comparison sites. EB methodology requires an accident prediction model which is a multivariate regression formula that fits collision data for comparison intersections to an independent set of variables that may be expected to affect safety. Recent crash studies have utilized Poisson, negative binomial, and gamma regression models to develop accident prediction models. Since the distribution of motor vehicle crashes can be overdispersed or underdispersed, the most appropriate model must be determined using goodness of fit testing. The purpose of this study is to develop an accident prediction model for motor vehicle crashes occurring in Miami-Dade County, Florida during 2008-2011.

Methods: Motor vehicle crash data were extracted from the Florida Department of Motor Vehicle and Highway Safety dataset for 40 intersections within Miami-Dade County, Florida for development of an accident prediction model (i.e. safety performance function. Each intersection selected was matched at least one of 20 intersections with red light cameras (RLC's) using selected geometric variables (number of lanes \& speed limit for major and minor roads) and average daily traffic. In addition, each intersection examined was at least 2 miles away from any RLC site. The dependent variable
\end{abstract}


examined was the number of injury crashes occurring at each intersection between 2008 and 2011. Poisson, negative binomial, and gamma model distributions were compared using goodness of fit tests. To measure the goodness of fit tests, the following criterions were used: Pearson's chi square $\left(\chi^{2}\right)$, scaled deviance $\left(\mathrm{G}^{2}\right)$, and Akaike Information Criterion (AIC).

Results: The negative binomial distribution was the best fit among the three models. Inspection of the observed data also suggested that the outcome variable's distribution was overdispersed. The negative binomial model achieved a Scaled Deviance/DF of 1.22 and a Pearson Chi-Squared/DF ratio of 1.09. In contrast, the Poisson model resulted in a scaled deviance/DF and chi square/DF ratios of 5.17 and 5.06, respectively. The log likelihood ratio for the two models resulted in a chi square value of 76.14 suggesting that the negative binomial distribution a better fitting model. The gamma distributed model's scaled deviance/DF and log-likelihood values were similar to the negative binomial model, however, the gamma model's Pearson Chi-Square/DF ratio was only 0.24. In addition, the AIC value for the gamma model (304.53) was slightly higher in comparison to the negative binomial model (303.92). The overdispersion parameter value for the negative binomial model was $0.16,95 \%$ CI $(0.09,0.29)$. The gamma model's dispersion parameter $(\alpha)$ was estimated to be $0.23,95 \% \mathrm{CI}(0.15,0.35)$, indicating, as in the negative binomial model, that overdispersion was present.

Conclusion: This study suggested that the negative binomial regression model provided the best fit among the distributions examined. This study also provided guidance on the use of Goodness of fit testing (GOF) statistics for Poisson, negative binomial, and gamma models which will allow other researchers to evaluate different models. 


\section{Introduction}

During 2012, approximately $48 \%$ of U.S. crashes occurred at an intersection or were intersection-related, of which over half (53\%) were signalized (National Highway Traffic Safety Administration [NHTSA], 2014). This indicates an excessive proportion of crashes transpire at signalized intersections considering they constitute only $10 \%$ all intersections within the U.S. (Federal Highway Administration, 2010). In addition, crashes at signalized intersections result in considerable numbers of injuries and fatalities. Approximately, 4,460 fatal crashes and 840,000 injury crashes occurred at a signalized intersection during 2012 (NHTSA, 2014). Despite national prevention efforts targeting this public health problem, the proportion of fatal crashes occurring at intersections with traffic signals increased 35\% between 2000 and 2012 (NHTSA, 2014; NHTSA, 2001). Numerous signalized intersection crashes can be attributed to red light running which accounts for $22 \%$ of urban collisions and over one-fourth of all injury collisions (Retting et al. 1995). According to the U.S. Department of Transportation, approximately $56 \%$ of Americans acknowledge running a red light (Romano et al. 2005).

The Insurance Institute for Highway Safety (IIHS) estimated 683 persons were killed as the result of a red light running crash and another 133,000 persons were injured during 2012 (IIHS, 2014). In addition, half of those killed in red-light running crashes are not signal violators, but the drivers and pedestrians who were struck (IIHS, 2007). The costs associated with red light running crashes are also significant. An examination of the safety impact of red light running crashes at intersections in the state of Texas found these crash types have a societal cost of $\$ 2$ billion annually statewide (Bonneson and Zimmerman, 2004). 
Several interventions have been implemented to decrease the risk of red light running crashes, including police enforcement, educational campaigns, and engineering modifications such as signal timing changes. Red light cameras (RLCs), however, are increasingly being used to discourage red light runners and decrease related crashes. Determining whether RLCs are effective is difficult for several reasons (Shin and Washington, 2007). One issue is the phenomenon known as regression to the mean (RTM). Since cameras are typically installed at sites with the highest number of violations and/or crashes instead of random assignment, subsequent reductions in the event analyzed could simply be due to RTM, that is, data falling in line with the average results found in the area, even with or without any intervention implementation. If not accounted for, results may be biased in estimating the benefit of RLCs (Retting et al. 2003).

Models that employ an Empirical Bayes analysis allow researchers account for RTM bias by estimating the number of collisions based on crash counts prior to RLC installation at treatment and comparison sites. The Empirical Bayes method requires an accident prediction model (i.e. safety performance function (SPF)) which is a multivariate regression formula that fits collision data for comparison intersections to an independent set of variables that may be expected to affect safety such as speed limit or number of straight-through lanes. SPF's are used to assist agencies in network screening processes, that is, identifying sites that may benefit from a safety treatment. In addition, SPFs can be instrumental for countermeasure comparisons, and project evaluations (US Department of Transportation, 2001). To properly develop an SPF using motor vehicle crash data, the best fit model must be determined. Although linear regression models can 
be thought of as a good starting point, most researchers decline to use this statistical method. Previous crash studies have elucidated the problems with linear regression models including a lack of a distribution to sufficiently explain random, discrete, nonnegative, and sporadic events such as motor vehicle accidents (Miaou and Lum, 1993. Due to these problems, subsequent crash studies have adopted other models to develop SPF's including 1) Poisson regression, which is used to analyze data that are Poisson distributed and 2) negative binomial regression which accounts for overdispersion. Although these two models possess desirable characteristics to explain motor vehicle crashes, they are not without limitations. One difficulty is that the two models do not account for underdispersion, where the variance of the data is less than its mean. Although this phenomenon is uncommon in crash analysis, it has been observed by various authors (Oh et al. 2006; Cameron and Trivedi, 1988). One model that has been proposed to handle underdispersion is the gamma probability count model (Winklemann \& Zimmermann, 1995). This model can handle both over-dispersion and underdispersion and reduces itself to a Poisson model when the variance is roughly equal to the mean of the number of crashes. Since several types of models are used to develop an SPF, goodness of fit testing can be employed to select the most appropriate distribution. The purpose of this paper was to determine the best fit regression model for the development of an SPF using historical motor vehicle crash data at 40 comparison sites without RLCs.

\section{Methods}

The Poisson regression model is usually thought of as the starting point in developing an SPF since crash data are routinely Poisson distributed (Oh et al. 2006). 
Poisson regression models are suited for motor vehicle crash analysis for several reasons, including analyzing events that occur randomly and independently over time (Karlaftis and Golias, 2002) along with handling smaller sample sizes than linear regression (Jovanis and Chang, 1986). In a poisson regression model, the probability of intersection $i$ having $y_{i}$ crashes per period is given by

$P\left(y_{i}\right)=\frac{\exp \left(-\lambda_{i}\right) \lambda_{i}^{y_{i}}}{y_{i} !} \quad i=0,1,2, \ldots$

where;

$P\left(y_{i}\right)=$ probability of roadway i having $y_{i}$ crashes/period,

$y_{i}=$ number of crashes for roadway i/period, and

$\lambda_{i}=$ expected number of crashes per period, $\mathrm{E}\left(y_{i}\right)$, also known as the Poisson parameter for roadway i.

The relationship between independent variables and expected number of crashes per period is a log-linear model of the following form:

$\operatorname{Ln}\left(\lambda_{\mathrm{i}}\right)=\boldsymbol{\beta} \mathbf{X}_{\mathrm{i}}$ or $\lambda_{\mathrm{i}}=\exp \left(\boldsymbol{\beta} \mathbf{X}_{\mathbf{i}}\right)$

where;

$\ln =$ natural logarithm

$\boldsymbol{\beta}=$ vector of regression parameters

$\mathbf{X}_{\mathrm{i}}=$ a vector of explanatory variables

The model coefficients are estimated through maximum likelihood methods. The likelihood function for the Poisson regression model is given as:

$$
L(\beta)=\prod_{i=1}^{n} \frac{\left[\exp \left(-\exp \left(\beta X_{i}\right)\right)\right]\left[\exp \left(\beta X_{i}\right)\right]^{y i}}{y_{i} !} \quad i=0,1,2, \ldots n
$$


Poisson regression models assume equality of the mean and variance, which on occasion, is not found in crash data. Studies have shown that accident data can be overdispersed, that is, the variance exceeds the mean (Karlaftis and Golias, 2002). When overdispersion exists, it tends to underestimate the variance of the model coefficients (Abdel-Aty and Radwan, 2000). To account for overdispersion, a negative binomial distribution is used as an alternative to the Poisson model. The negative binomial distribution introduces an overdispersion parameter which corrects for the variance and mean difference. As the overdispersion parameter approaches zero, the negative binomial distribution converges into a Poisson distribution. The probability function for the negative binomial regression model is given below:

$P\left(y_{i}\right)=\frac{\Gamma\left(y_{\mathrm{i}}+\frac{1}{\alpha}\right)}{y_{i} ! \Gamma\left(\frac{1}{\alpha}\right)}\left(\frac{1}{1+a \lambda_{i}}\right)^{1 / a}\left(\frac{\lambda_{i}}{\left(\frac{1}{a}\right)+\lambda_{i}}\right)^{y_{i}} i=0,1,2, \ldots$

where;

$\Gamma(\cdot)=$ gamma function

$y_{i}=$ number of crashes per period for intersection i and,

$\alpha=$ overdispersion parameter

Considering n number of crashes, the likelihood function is given by:

$L\left(\lambda_{i}\right)=\prod_{i=1}^{n} \frac{\Gamma\left(y_{i}+\frac{1}{a}\right)}{y_{i} ! \Gamma\left(\frac{1}{a}\right)}\left(\frac{1}{1+a \lambda_{i}}\right)^{\frac{1}{a}}\left(\frac{\lambda_{i}}{\left(\frac{1}{a}\right)+\lambda_{i}}\right)^{y_{i}} i=0,1,2, \ldots n$ 
The primary advantage of the negative binomial distribution over the poisson distribution is that the overdispersion parameter provides increased flexibility into the modeling of the variance function, allowing the variance to differ from the mean. Thus, the negative binomial model can be an appropriate model to address these challenges. A limitation, however, of both Poisson and negative binomial models is its inability to handle underdispersion (Lord and Mannering, 2010), that is, when the mean exceeds the variance. As a result, gamma models have been proposed to handle underdispersed crash data (Oh et al. 2006; Winkelmann, 1995). The gamma probability model can be given as: $\operatorname{Pr}\left[y_{i}=j\right]=\operatorname{Gam}\left(\alpha j, \lambda_{i}\right)-\operatorname{Gam}\left(\alpha j+\alpha, \lambda_{i}\right) ; \quad i=0,1,2, \ldots$ where; $\lambda_{i}=\exp \left(\beta^{\prime} X_{i}\right)$ $\operatorname{Gam}\left(\alpha j, \lambda_{i}\right)=1$, if $\mathrm{j}=0$, or $\frac{1}{\Gamma(a j)} \int_{0}^{\lambda_{i}} u^{\alpha j-1} e^{-u} d u$, if $\mathrm{j}>0, \mathrm{j}=0,1, \ldots$

The dispersion parameter is $\alpha$, as in the negative binomial model. The value of $\alpha$ determines whether there is overdispersion, underdispersion, or equidispersion. If $\alpha>1$, there is evidence of underdispersion. In contrast, if $\alpha<1$, there is overdispersion, and lastly, equidispersion if $\alpha=1$, which reduces itself to a Poisson model. The conditional mean function and cumulative distribution function for the gamma probability model can be found in Oh et al. 2006.

\section{Data description}

Forty intersections within Miami-Dade County, Florida were selected for development of the SPF. Each intersection selected had been previously matched to at least one of 20 intersections with RLC's with respect to selected geometric and daily 
traffic variables. These variables included the intersection's annual average daily traffic (AADT) across all approaches and the total number of lanes and average speed limits for the intersection's major and minor roads. In addition, each selected intersection was at least 2 miles away from any RLC site. Crash records for the selected intersections were extracted from the Florida Department of Motor Vehicle and Highway Safety dataset. Crashes were selected using several criteria:

1) The crash occurred between 2008 and 2011.

2) The crash occurred within 150 feet of the intersection

3) The crash resulted in at least one injury or fatality

4) The accident did not result in solely pedestrian or bicyclist injuries/fatalities.

The dependent variable was the number of injury crashes.

Goodness of fit testing (GOF) was used to determine the best fit model. GOF uses the properties of a hypothesized distribution to determine whether observed data can be generated from a given distribution (Read and Cressie, 1988; Khan et al. 2014a). Widely used GOF test statistics include the Pearson's chi square $\left(\chi^{2}\right)$ and scaled deviance $\left(\mathrm{G}^{2}\right)$. As described in Ye et al. (2013), the Pearson's chi square value is calculated as:

$\chi^{2}=\sum_{i=1}^{n}\left[y_{i}-u_{i} / \sigma_{i}\right]^{2}$

where;

$y_{i}$ is the observed data,

$u_{i}$ is the true mean from the model, and $\sigma_{i}$ is the error and is usually represented by the standard deviation of $y_{i}$. 
The scaled deviance value is computed as twice the difference between the log likelihoods under the alternative and null model. A third test, Akaike Information Criterion (AIC) is also commonly used to measure model GOF. The model is defined as: $A I C=[-2 \log ($ likelihood $)+2 p]$,

where likelihood is the probability of the data given a model and $p$ is the number of parameters in the model. Lower AIC values indicates a better model fit of the data (Khan et al. 2014; Khan et al. 2014b). These three tests were used to select the most appropriate SPF model. SAS 9.2 was used to develop the Poisson, negative binomial, and gamma models using the generalized linear model (GENMOD) procedure. The GENMOD procedure for each distribution produced Pearson's chi square, scaled deviance, loglikelihood, and AIC values, which were subsequently compared to select the best model fit.

\section{Results}

\section{Intersection Characteristics}

Descriptive characteristics for the 40 comparison sites are displayed in Table 1. Independent variables included the intersection's logarithmic mean AADT across all approaches, mean speed limit \& mean number of lanes for the major and minor roads, along with their ranges, standard deviations, and 95\% confidence intervals.

Results of the poisson regression model are shown in Table 2 below. For the Poisson model, log [mean AADT], mean speed limit (minor road), number of lanes (minor road), were found to be statistically significant at $\alpha=0.05$. In contrast, the negative binomial model indicated, as shown in Table 3, log [Mean AADT] and mean speed limit (minor road) were the only statistically significant variables. The negative 
binomial model's overdispersion parameter value was $0.16,95 \% \mathrm{CI}(0.09,0.29)$. Since the confidence interval did not overlap zero, thus indicates that overdispersion was present in the crash data, that is, the variance exceeded the mean.

The gamma model was then estimated to test for underdispersion and as shown in Table 4 , the dispersion parameter $(\alpha)$ was estimated to be 0.23 . In addition, the $95 \% \mathrm{CI}$ did not overlap one indicating, as in the negative binomial model, that overdispersion was present. The gamma model's significant variables included the log [mean AADT] and speed limit (minor road).

\section{Model goodness of fit}

The model GOF for the Poisson, negative binomial, and gamma distributions were measured using the scaled deviance, Pearson Chi-squared Statistic, and AIC tests. The ratios of the scaled deviance and Pearson Chi-Square values to the model's degrees of freedom (DF) were then calculated to determine GOF with values close to 1 suggesting a good fit. All GOF test results are presented in Table 5. The negative binomial model achieved a Scaled Deviance/DF of 1.22 and a Pearson Chi-Squared/DF ratio of 1.09. In contrast, the Poisson model resulted in a scaled deviance/DF and chi square/DF ratios of 5.17 and 5.06, respectively. The log likelihood ratio for the two models resulted in a chi square value of 76.14 suggesting that the negative binomial distribution was a better fitting model. The gamma distributed model's scaled deviance/DF and log-likelihood values were similar to that of the negative binomial model, however, the gamma model's Pearson Chi-Square/DF ratio was only 0.24. In addition, the AIC value for the gamma model was slightly higher in comparison to the 
negative binomial model. Based on Table 5's results and evidence of overdispersion in Tables $3 \& 4$, the negative binomial model provided the best fit for developing the SPF.

\section{Discussion}

We considered three different regression models using motor vehicle crash data at 40 comparison intersections to develop an SPF for Empirical Bayes analysis. The regression models examined were Poisson, negative binomial, and gamma distributions. We fit each of these models to crash data from 2008 - 2011 in which the outcome variable was the count of injury crashes. GOF measurements indicated that the negative binomial distribution provided the best fit among the three models examined. Inspection of the observed data also suggested that the outcome variable's distribution was overdispersed, indicating that the negative binomial model was better suited to handle overdispersed data compared to the Poisson and gamma distributions. Similarly, the gamma model's parameter estimates indicated that overdispersion, and not underdispersion was present.

The negative binomial distribution is especially useful for count data whose variance exceeds the sample mean. In vehicle crash data, counts frequently depart from the Poisson distribution due to larger frequencies of extreme observations resulting in a greater variance compared to the mean, resulting in over-dispersion (Hu et al. 2011), which was evident in our analysis. Although underdispersion can occasionally occur when analyzing motor vehicle crash data, it was not present according to our results. 
A limitation of this analysis was the small number of injury crashes at each site. This was expected since injury crashes are infrequent. Approximately $29 \%$ of all crashes in the United States results in at least one injury/fatality (NHTSA, 2014). In this study, two or three additional crashes may had influenced the results if few sites $(4-5$ intersections) were examined, however, by selecting a larger number of comparison sites this impact was reduced. Other possibilities to further improve the model fit would be to increase the number of crashes by examining additional intersections or using a longer study period. If using a longer study period however, one must be aware that any changes made to a site (i.e., increased number of lanes, law changes) during the period of analysis may be more likely, rendering the results of that site invalid.

The negative binomial model is currently one of the most common type of model employed in vehicle crash analysis (Ye et al. 2013). On some occasions, however, the Poisson model can also be a suitable model. Gamma distributed regression models, although relatively new to vehicle crash analysis, is being seen as an alternative to both the Poisson and negative binomial models. Crash frequency data can present several issues in terms of data characteristics, thus new methodological approaches are constantly being introduced (Lord and Mannering, 2010). Thus, future studies can be conducted to examine vehicle crash data using novel statistical approaches. This study provided guidance on the use of GOF statistics for Poisson, negative binomial, and gamma models which will allow other researchers to evaluate different models. Our results suggest the importance of comparing different probability distributions when modeling crash frequency data, particularly when overdispersion and underdispersion may exist. 


\section{References}

National Highway Traffic Safety Administration. National Center for Statistics and Analysis, U.S. Department of Transportation. (2014). Traffic Safety Facts 2012. A Compilation of Motor Vehicle Crash Data from the Fatality Analysis Reporting System and the General Estimates System. Report Number: DOT HS 812032. Available at: http://www-nrd.nhtsa.dot.gov/pubs/812032.pdf.

Federal Highway Administration. Safety at Signalized Intersections (Short Version). 2010. Available at http://safety.fhwa.dot.gov/intersection/signalized/presentations/sign_int pps0515 $\underline{08 / \text { short//). }}$

National Highway Traffic Safety Administration. National Center for Statistics and Analysis, US Department of Transportation. 2001. Traffic Safety Facts 2000. A Compilation of Motor Vehicle Crash Data from the Fatality Analysis Reporting System and the General Estimates System. Available at: http://wwwnrd.nhtsa.dot.gov/Pubs/TSF2000.pdf.

Retting RA, Williams AF, Preusser DF, Weinstein HB. Classifying urban crashes for countermeasure development. Accident Analysis and Prevention. 1995; 27(3):283-294.

Romano E, Tippetts AS, Voas R. Fatal red light crashes: The role of race and ethnicity. Accident Analysis and Prevention. 2005; 37(3), 453-460.

Insurance Institute for Highway Safety. Red Light Running. 2014. Available at: http://www.ihs.org/iihs/topics/t/red-light-running/topicoverview

Insurance Institute for Highway Safety. Status Report, 2007; 42(1), Available at: http://www.iihs.org/externaldata/srdata/docs/sr4201.pdf

Bonneson J \& Zimmerman K. Federal Highway Administration. Development of guidelines for identifying and treating locations with a red light running problem. 2004. Report Number FHWA/TX-05/0-4196-2.

Shin K \& Washington S. The impact of red light cameras on safety in Arizona. Accident Analysis and Prevention. 2007; 39(6):1212-1221.

Retting RA, Ferguson SA, \& Hakkert, AS. Effects of red light cameras on violations and crashes: A review of the international literature. Traffic Injury Prevention. 2003; 4(1):17-23. 
US Department of Transportation, Federal Highway Administration. 2001. Revised assessment of economic impacts of implementing minimum levels of pavement marking retroreflectivity. Report Number: FHWA-SA-10-016.

Miaou SP \& Lum H. Modeling vehicle accidents and highway geometric design relationships. Accident Analysis and Prevention. 1993; 25(6):689-709.

Oh J, Washington SP, Nam D. Accident prediction model for railway-highway interfaces. Accident Analysis and Prevention. 2006; 38(2): 346-356.

Cameron AC \& Trivedi PK. Regression Analysis of Count Data. Cambridge University Press, Cambridge, MA, 1988.

Winklemann R \& Zimmermann KF. Recent developments in count data modelling: Theory and application. Journal of Economic Surveys. 1995; 9(1):1-20.

Karlaftis MG \& Golias I. Effects of road geometry and traffic volumes on rural roadway accident rates. Accident Analysis and Prevention. 2002; 34(3):357-365.

Jovanis PP \& Chang HL. Modeling the relationship of accidents to miles traveled. Transportation Research Record. 1986; 1068:42-51.

Abdel-Aty MA, Radwan AE. Modeling traffic accident occurrence and involvement. Accident Analysis and Prevention. 2000; 32(5):633-42.

Lord D \& Mannering F. The statistical analysis of crash-frequency data: A review and assessment of methodological alternatives. Transportation Research Part A: Policy and Practice. 2010; 44(5):291-305.

Winklemann R. Duration dependence and dispersion in count-data models. Journal of Business \& Economic Statistics. 1995; 13(4):467-474.

Read TRC \& Cressie N. Goodness-of-Fit Statistics for Discrete Multivariate Data. Springer-Verlag, New York, 1988.

Khan HMR, Saxena A, Rana S, Ahmed NU. Bayesian method for modeling male breast cancer survival data. Asian Pacific Journal Cancer Prevention. 2014a; 15(2), 663-669.

Ye Z, Zhang Y, Lord D. Goodness-of-fit testing for accident models with low means. Accident Analysis and Prevention. 2013; 61:78-86. 
Khan HFR, Saxena A, Ross E, Ramamoorthy V, Sheehan D. Inferential statistics from Black Hispanic breast cancer survival data. The Scientific World Journal of Probability and Statistics. 2014b. Available at: http://www.hindawi.com/journals/tswj/aip/604581/, 1 - 13.

Hu MC, Pavlicova M, Nunes EV. Zero-inflated and hurdle models of count data with extra zeros: examples from an HIV-risk reduction intervention trial. American Journal of Drug Alcohol Abuse. 2011; 37(5):367-75. 
Figures and Tables

Table 2.1 Manuscript 2:

Intersection characteristics for development of accident prediction model

\begin{tabular}{|c|c|c|c|c|}
\hline $\begin{array}{c}\text { Comparison } \\
\text { Intersections } \\
\mathbf{n = 4 0}\end{array}$ & $\begin{array}{c}\text { Mean } \\
\mathbf{2 0 0 8}-\mathbf{2 0 1 1}\end{array}$ & Range & $\begin{array}{c}\text { Standard } \\
\text { Deviation }\end{array}$ & $\begin{array}{c}\text { 95\% Confidence } \\
\text { Interval (C.I.) }\end{array}$ \\
\hline AADT (1000's) & 65.78 & $(30.83,108.40)$ & 21.58 & $(58.87,72.68)$ \\
\hline $\begin{array}{c}\text { Number of Lanes: } \\
\text { Major Road }\end{array}$ & 4.90 & $(2.00-7.00)$ & 1.22 & $(4.51,5.29)$ \\
\hline $\begin{array}{c}\text { Number of Lanes: } \\
\text { Minor Road }\end{array}$ & 3.68 & $(2.00-6.00)$ & 1.05 & $(3.34,4.01)$ \\
\hline $\begin{array}{c}\text { Speed Limit: } \\
\text { Major Road }\end{array}$ & 40.56 & $(35.00-45.00)$ & 1.92 & $(39.95,41.18)$ \\
\hline $\begin{array}{c}\text { Speed Limit: } \\
\text { Minor Road }\end{array}$ & 37.43 & $(30.00,40.00)$ & 3.56 & $(36.29,38.58)$ \\
\hline
\end{tabular}


Table 2.2 Manuscript 2:

Safety performance function Poisson regression parameter estimates

\begin{tabular}{|c|c|c|c|c|}
\hline Parameter & Estimate & Standard Error & $\mathbf{9 5 \%}$ C.I. & p-value \\
\hline Intercept & -10.52 & 1.47 & $(-13.39,-7.64)$ & $<0.01$ \\
\hline Log Mean AADT & 0.99 & 0.16 & $(0.68,1.29)$ & $<0.01$ \\
\hline $\begin{array}{c}\text { Speed Limit: } \\
\text { Major Road }\end{array}$ & 0.01 & 0.02 & $(-0.03,0.05)$ & 0.59 \\
\hline $\begin{array}{c}\text { Speed Limit: } \\
\text { Minor Road }\end{array}$ & 0.06 & 0.01 & $(0.03,0.09)$ & $<0.01$ \\
\hline $\begin{array}{c}\text { Street Lanes: } \\
\text { Major Road }\end{array}$ & 0.06 & 0.04 & $(-0.02,0.15)$ & 0.16 \\
\hline $\begin{array}{c}\text { Street Lanes: } \\
\text { Minor Road }\end{array}$ & -0.12 & 0.05 & $(-0.23,-0.02)$ & 0.02 \\
\hline
\end{tabular}


Table 2.3 Manuscript 2:

Safety performance function negative binomial regression parameter estimates

\begin{tabular}{|c|c|c|c|c|}
\hline Parameter & Estimate & Standard Error & $\mathbf{9 5 \%}$ C.I. & p-value \\
\hline Intercept & -12.12 & 3.39 & $(-18.76,-5.49)$ & $<0.01$ \\
\hline Log Mean AADT & 1.02 & 0.34 & $(0.35,1.69)$ & $<0.01$ \\
\hline $\begin{array}{c}\text { Speed Limit: } \\
\text { Major Road }\end{array}$ & 0.04 & 0.05 & $(-0.05,0.13)$ & 0.41 \\
\hline $\begin{array}{c}\text { Speed Limit: } \\
\text { Minor Road }\end{array}$ & 0.07 & 0.03 & $(0.02,0.12)$ & 0.01 \\
\hline $\begin{array}{c}\text { Street Lanes: } \\
\text { Major Road }\end{array}$ & 0.06 & 0.09 & $(-0.12,0.23)$ & 0.54 \\
\hline $\begin{array}{c}\text { Street Lanes: } \\
\text { Minor Road }\end{array}$ & -0.15 & 0.11 & $(-0.37,0.06)$ & 0.16 \\
\hline \begin{tabular}{c} 
Dispersion Parameter \\
\hline
\end{tabular} & 0.16 & 0.05 & $(0.09,0.29)$ & \\
\hline
\end{tabular}


Table 2.4 Manuscript 2:

Safety performance function gamma regression parameter estimates

\begin{tabular}{|c|c|c|c|c|}
\hline Parameter & Estimate & Standard Error & $\mathbf{9 5 \%}$ C.I. & p-value \\
\hline Intercept & -12.69 & 3.59 & $(-19.73,-5.67)$ & $<0.01$ \\
\hline Log Mean AADT & 1.02 & 0.36 & $(0.32,1.72)$ & $<0.01$ \\
\hline Speed Limit - Major Road & 0.05 & 0.05 & $(-0.05,0.15)$ & 0.32 \\
\hline Speed Limit - Minor Road & 0.07 & 0.03 & $(0.02,0.13)$ & 0.01 \\
\hline Street Lanes - Major Road & 0.06 & 0.09 & $(-0.12,0.25)$ & 0.51 \\
\hline Street Lanes - Minor Road & -0.16 & 0.11 & $(-0.38,0.06)$ & 0.15 \\
\hline Dispersion Parameter & 0.23 & 0.05 & $(0.15,0.35)$ & \\
\hline
\end{tabular}


Table 2.5 Manuscript 2:

Results of model goodness of fit tests for safety performance functions

\begin{tabular}{|c|c|c|c|c|}
\hline Distributions & $\begin{array}{c}\text { Scaled } \\
\text { Deviance/DF }\end{array}$ & $\begin{array}{c}\text { Pearson Chi-Square } \\
\text { Value/DF }\end{array}$ & $\begin{array}{c}\text { Log } \\
\text { AIC }\end{array}$ \\
\hline Likelihood \\
\hline Poisson & 1.22 & 1.09 & 303.92 & -144.96 \\
\hline Gamma & 5.17 & 5.06 & 378.05 & -183.03 \\
\hline
\end{tabular}




\section{CHAPTER IV}

MANUSCRIPT 3 - PRIMARY STUDY (ACCEPTED, IN PRESS)

Impact of Red Light Cameras on Motor Vehicle Injury Collisions within

Miami-Dade County, Florida 


\title{
MANUSCRIPT 3
}

\section{Impact of Red Light Cameras on Motor Vehicle Injury Collisions within Miami-Dade County, Florida}

\begin{abstract}
Objectives: To determine the safety effect of red light camera (RLC) programs, this study attempted to estimate its impact on collisions within Miami-Dade County, Florida

Methods: A before-after evaluation using a comparison group along with traffic control correction was employed. Twenty signalized intersections with RLCs which began enforcement on January 1st, 2011 were matched to two comparison sites located at least two miles from camera sites to minimize spillover effect. An Empirical Bayes analysis was used to account for potential regression to the mean effects. Rightangle/turning, rear-end, all injury, and red light running (RLR)-related injury were the collision types examined. An index of effectiveness along with 95\% CI's were calculated based on the comparison between the estimated and actual number of crashes in the after period.

Results: During the first year, RLC sites experienced a marginal decrease in right-angle/turn collisions (-3\%), a significant increase in rear-end collisions $(+38 \%)$, and significant decreases in all-injury (-19\%) and RLR-related injury collisions (-25\%). An increase in right-angle/turning $(+13 \%)$ and rear-end $(+49 \%)$ collisions at the RLC sites was observed after two years despite camera enforcement. A significant reduction in RLR-related injury crashes (-17\%), however, was still observed after two years. A nonsignificant decline in all injury collisions $(-11 \%)$ was also noted.
\end{abstract}


Conclusion: RLCs showed a benefit in reducing RLR-related injury collisions at camera sites after enforcement commenced, yet its tradeoff was a large increase in rearend collisions. There was inconclusive evidence whether RLC's affected rightangle/turning and all injury collisions. Statutory changes in crash reporting during the second year of camera enforcement affected the incidence of right-angle and rear-end collisions, nevertheless, a "novelty effect" could also not be ruled out. Future research should consider events such as low frequencies of severe injury/fatal collisions and changes in crash reporting requirements when conducting RLC analyses.

\section{Introduction}

During 2012, approximately $48 \%$ of U.S. crashes occurred at an intersection, of which over half $(53 \%)$ took place at roads with traffic signals (National Highway Traffic Safety Administration (NHTSA), 2014). This indicates an excessive proportion of crashes transpire at signalized intersections considering they constitute only $10 \%$ all U.S. intersections (Federal Highway Administration (FHA), 2010). During 2011, one-tenth of all fatal crashes in the U.S. occurred at signalized intersections. In addition, nearly onethird of traffic signal crashes resulted in at least one occupant injury (NHTSA, 2010). Despite national prevention efforts, the percentage of fatal crashes occurring at intersections with traffic signals increased 5\% between 2000 and 2009 (NHTSA, 2001; 2011). Many crashes at signalized intersections can be attributed to red light running. Approximately 56\% of Americans acknowledge running red lights (Retting \& Williams, 1996). The Insurance Institute for Highway Safety (IIHS) estimates 683 persons were killed as the result of red light running crashes and another 133,000 persons were injured (IIHS, 2014). The IIHS also states that half of those killed in red-light running crashes are 
not the signal violators but drivers and pedestrians hit by red-light runners (IIHS, 2007). Costs associated with red light running crashes are also significant. An examination in Texas found these crash types have a societal cost of $\$ 2$ billion annually statewide (Bonneson \& Zimmerman, 2004).

Several interventions have been implemented to decrease the risk of red light running crashes, including police enforcement, educational campaigns, and engineering modifications such as signal timing changes. Red light cameras (RLCs), however, are increasingly being used to discourage red light runners and decrease related crashes. Several articles have been published regarding their effectiveness, however, results have been mixed.

Determining whether RLCs are effective is difficult for several reasons (Shin \& Washington, 2007). Since cameras are typically installed at sites with the highest number of violations and/or crashes instead of random assignment, subsequent reductions in the event analyzed (e.g., crash frequency) could simply be due to regression to the mean (RTM), that is data falling in line with the average results found in the area, even with or without any intervention implementation. If not accounted for, results may be biased in estimating the benefit of RLCs (Retting et al. 2003). As a result, many studies employ Empirical Bayes (EB) analyses which addresses the RTM effect whereby extreme measurements are drawn towards the mean.

Shin and Washington (2007) examined the impact of RLCs to reduce crashes on 24 intersections in Scottsdale and Phoenix, Arizona. In Scottsdale, a simple before-after methodology was designed using an EB analysis, while in Phoenix a before-after study with a comparison group was used. Bayesian analysis was not employed for the Phoenix 
comparison. In Scottsdale, the authors found, 1) a non-significant 20\% decline in right angle crashes, 2) a significant $45 \%$ decrease in left turn crashes, and 3) a significant $41 \%$ increase in rear-end collisions. In Phoenix, right angle crashes declined by $42 \%$ while rear-end crashes increased by $20 \%$, both of which were significant. No change in total crashes was evident for either city. Hallmark et al. (2010), employed a Bayesian analysis to compare crash incidence at four intersections with RLCs to five control sites in Davenport, Iowa. Control sites were similar to RLC intersections with respect to traffic volume and crash frequencies. The authors found a barely significant $20 \%$ decline in the rate of total collisions at RLC intersections and a $40 \%$ reduction in red light running crash rates for the camera sites. No difference in red light running crashes was observed for the control intersections. Lastly, no change in rear-end crashes was evident for either the intervention or control sites.

Spillover effects caused by RLCs influencing a driver's behavior to extend to sites beyond camera-equipped intersections may bring out a positive, area-wide effect, that is, a reduction in crashes and injuries for both RLC and nearby non-treatment sites. Violation rate declines of $33-50 \%$ at comparison sites have been previously observed due to spillover effects (Retting et al. 1999a; Retting et al. 1999b). Ahmed \& Abdel-Aty (2014) examined the impact of motor vehicle crashes at 25 RLC equipped intersections within Orange County, Florida using an EB analysis. Crashes at fifty non-RLC intersections located within the vicinity of camera sites were also collected to examine spillover effects. Results indicated that RLC sites experienced a significant reduction in angle and left turn crashes and a significant increase in rear-end collisions. Similar trends were also observed in the nearby sites, indicating a spillover effect. 
Although recent studies have accounted for effects such as RTM and spillover, few have examined the impact of RLC's on injury collisions which should also be evaluated to determine the safety effect of RLC programs, Therefore, this study attempted to estimate the impact of RLCs on injury crashes at signalized intersections within Miami-Dade County by applying current methodologies.

\section{Methods}

A before-after study was employed to determine whether reduced injury crashes at signalized intersections are associated with RLCs. The methodology consisted of a before-after evaluation using a comparison group along with traffic control correction. An EB analysis was used to account for potential RTM effects. The study was conducted in Miami-Dade County, Florida which has an estimated population of 2.5 million and a land area of 1,946 square miles. A statewide RLC law took effect in July 1st, 2010, permitting selected municipal governments to establish local camera enforcement programs. RLC enforcement in Miami-Dade County began in January 2011 which was preceded by a 30-day warning period during December 2010, whereby cameras were used to photograph violators, but no tickets were issued. Signs advising motorists of photo enforcement of traffic-signal laws were posted on all RLC locations. Warning signs were placed between 150 and 300 feet from the intersection's stop line, depending on the approach speed limit. City officials also attempted to generate publicity and awareness of the program by issuing press releases and providing information to local media.

Camera locations were determined by contacting municipalities directly. A list of 20 RLCs was obtained from various municipalities that initiated camera enforcement of red 
light runners on January $1^{\text {st }}, 2011$ to use in the study. The Miami-Dade County Geographic Information Systems (GIS) Self Services Data Download website (http://www.miamidade.gov/technology/gis-self-service.asp) was then accessed to geocode all intersections using its corresponding longitudinal and latitudinal values using ARCMAP Desktop (version 10.0).

Intersection characteristics were obtained using the Florida Department of Transportation (FDOT) GIS Roadway Characteristics Inventory (RCI) website (http://www.dot.state.fl.us/planning/statistics/gis/). This website is comprised of shapefiles for most major roadways in Florida and contain several variables pertaining to roadway characteristics including speed limit, current annual average daily traffic, number of lanes, and median width. They were then added to the map using ARCMAP Desktop's clipping tool to display only Miami-Dade roadways. Historical Miami-Dade roadway AADT data was obtained via the FDOT Florida traffic online website: http://www2.dot.state.fl.us/FloridaTrafficOnline/viewer.html.

\section{Intervention and Comparison Site Selection}

Signalized intersections were divided into two groups, those with and without RLCs. The 20 RLC intersections were classified as intervention sites Each RLC intersection was then matched to 2 comparison sites ( 40 total) with similar geometric layouts using the following variables:

- Major road speed limit

- Minor road speed limit

- Total annual average daily traffic (AADT) for all approaches

- Number of lanes: major road 
- Number of lanes: minor road

To minimize spillover effect, comparison sites were located at least two miles from an RLC intersection. Since Florida allows the use of RLCs throughout the state, it is not suitable to select comparison sites located outside a city, as they are usually located outside of the enforcing community (Retting et al. 2003; Retting et al. 2002). Currently, Miami-Dade County RLC's are only located within municipalities and not in unincorporated areas. Therefore, it is assumed that spillover effects on comparison sites isolated from RLC's would be reduced. A two-mile buffer zone for each RLC intersection was created to reduce the likelihood for spillover effects. Any signalized intersections located within buffer zones were excluded as possible comparison sites. Our decision to use a two mile buffer zone was based on a recent study evaluating the effectiveness of RLC's in Texas which used a similar radius for comparison sites (Ko et al. 2013). Additionally, Wong (2014) concluded that spillover effect should be strongest for a $1 / 2$ mile and weakest for two mile buffer zones.

\section{Defining Injury Crashes}

Miami-Dade County collision information was obtained from the Florida Traffic Crash Records Database (FTCRD). Crashes were analyzed for three years before (2008 2010) and two years after camera enforcement (2011 \& 2012). Crashes at intervention and comparison sites were included if occurring within 150 feet from the center of an intersection.

Crashes related to RLCs can be categorized into: those attributed to red light running (RLR), and those caused by actions related to avoiding RLR (Shin \& Washington, 2007). Therefore, four types of motor vehicle crashes, right-angle, rear-end, 
left-turn, and right-turn were included according to FTCRD variables. Injury collisions were limited to crashes with an injury code of either "fatal", "incapacitating injury", "non-incapacitating evident injury", or "possible injury". They were then classified into two collision categories, all injury and RLR-related injury. Due to an insufficient number of fatal and incapacitating injury crashes, all injury severity crash levels were collectively aggregated. For similar reasons, right-angle/turning collisions were also combined.

\section{Variable Selection \& Statistical Analysis}

Right angle/turn, rear-end, all injury, and RLR-related injury crashes were the outcome variables of interest. Independent continuous variables consisted of the total number of straight-through lanes \& speed limits for the major and minor approaches, and total AADT for all approaches.

As previously stated, failing to account for RTM may overestimate the benefits of RLCs, therefore, Bayesian analyses can be used to address this weakness. Models that employ Bayesian analyses allow researchers to estimate collision rates without the treatment based on crash occurrence prior to RLC enforcement at the comparison sites. EB methodology assumes that crash occurrence fit either a Poisson or negative binomial (NB) distribution.

Poisson regression models are often thought of as a starting point for crash data, however, it assumes equality of the mean and variance. Studies have shown that crash data can be overdispersed, that is, the variance exceeds the mean (Karlaftis \& Golias, 2002). When overdispersion exists, it tends to underestimate the variance of the model coefficients (Abdel-Aty et al. 2005). To account for overdispersion, a NB distribution is used as an alternative. The NB distribution introduces an overdispersion parameter which 
corrects for the variance and mean difference. As the overdispersion parameter approaches zero, the NB distribution converges into a Poisson distribution. The primary advantage of the NB distribution is that the overdispersion parameter provides increased flexibility into the modeling of the variance function, allowing the variance to differ from the mean. Thus, the NB model is an appropriate model to address these challenges and is currently the most common model used in motor vehicle crash data (Lord and Mannering, 2010).

A before-after analysis using the EB method was employed to evaluate the safety effectiveness of the 20 RLC's. A safety performance function (SPF) was generated on the 40 comparison intersections using a NB regression model. An SPF is a statistical regression model which fits collision data for comparison intersections to an independent set of variables which may be expected to affect safety such as road speed limits. The SPF is estimated by maximum likelihood and commonly assumes a NB distribution for the crash data. An example of an SPF predicting the number of crashes at an intersection is provided below:

$S P F_{i}=\exp \left[\beta_{0}+\beta_{1} \ln (A A D T)+\beta_{2} \quad\right.$ (Speed Limit $\left.)\right]$ where:

$S P F_{i}$ is the predicted number of crashes at intersection $i$ and $\beta_{i}$ 's are regression parameters

SPF's are used to assist agencies in network screening processes, that is, identifying sites that may benefit from a safety treatment. In addition, SPFs can be instrumental for countermeasure comparisons, and project evaluations (Federal Highway Administration, 2010). 


\section{Empirical Bayes Calculation}

A thorough explanation on how EB estimators are derived can be found in Shin \& Washington (2007). The EB method estimates the expected crash frequency at the RLC intersection in the after period had the intervention not been implemented using the crash history of the treatment and comparison sites. To estimate the number of crashes for each RLC site before installation, the characteristics of each treated intersection are inserted to the SPF model and a ratio of the before period to the overall period length examined is obtained to normalize the length of time estimate. This results in $\hat{E}[\kappa]$, the expected number of crashes in the before period for each RLC intersection based on the SPF model. To calculate the estimate of the number of after-period crashes at the RLC sites had it not been treated $\left(\mathrm{M}_{\mathrm{i}}\right)$, a weighted average $\left(\mathrm{W}_{\mathrm{i}}\right)$ is taken between the SPF estimate $\hat{E}[\kappa]$, and actual before-period observed number of collisions (Shin \& Washington, 2007).

$M_{i}=W_{i} * \hat{E}[\kappa]+\left(1-W_{i}\right) * K_{i}$,

where:

$K_{i}$ : Observed collisions in the before period at intersection $\mathrm{i}$

$W_{i:}$ Weight for intersection i where:

$W i=\frac{\widehat{\mathrm{E}}[\kappa]}{\widehat{\mathrm{E}}[\kappa]+\widehat{\operatorname{Var}}[\kappa]} ; \widehat{\operatorname{Var}}[\kappa]=\widehat{\mathrm{E}}^{2}[\kappa] * \alpha$

with $\alpha$ being the overdispersion parameter which is generally of the form (Cameron \& Trivedi, 1999):

$\alpha=\exp \left(\frac{\beta_{0}+\beta_{1} \mathrm{X}_{i, i}+\beta_{2} \mathrm{X}_{, i+. .} \beta_{i} \mathrm{X}_{i}}{\mathrm{X}_{1, i}}\right)$

where: $\beta^{\prime}$ s are a vector of covariates and $X^{\prime}$ s are a set of independent variables. 
If a large amount of variability in the observed data exists, the overdispersion parameter will be higher, therefore applying more weight to the SPF. In contrast, if there is little variability, less weight will be applied to the SPF and more to the observed data. Since $\mathrm{M}_{i}$ is an estimate based on the length of the before period, it is normalized to the after period. Thus, the estimate of the after-period crashes $\left(\pi_{\mathrm{i}}\right)$ for intersection $\mathrm{i}$ is:

$\pi_{i}=M_{i} * C_{i} * A A D T_{i}$

where: $\mathrm{C}_{\mathrm{i}}$ : Ratio of after period to the before period and

$A A D T_{i}=\frac{A A D T_{\text {after }}^{\alpha_{1}}}{A A D T_{\text {before }}^{\alpha_{1}}}$

where: $A A D T_{\text {after }}$ is the AADT at the RLC site in the after period, $A A D T_{\text {before }}$ is the AADT at the RLC site in the before period, and $\alpha_{1}$ is the regression coefficient of AADT from the SPF.

The total number of expected crashes across all 20 RLC sites during the after period is then summed using Eq. 6.

$\pi=\sum_{i} \pi_{i}$

An index of effectiveness, which measures how effective the treatments were, is based on the comparison between the estimated and actual number of injury crashes in the after period. To measure the index of effectiveness $(\theta)$, the estimate obtained in Eq. 6 is compared to the actual number of crashes after RLC enforcement. The formula to estimate $\theta$ is:

$\Theta=\frac{L / \pi}{\left(1+\frac{\operatorname{var}(\pi)}{\pi^{2}}\right)}$

where, 
$\mathrm{L}$ - The total number of injury crashes in the after period for all 20 RLC intersections and:

$\operatorname{Var}(\pi)=\sum_{i} C_{i}^{2} * A A D T_{i}^{2} *\left(1-W_{i}\right) * M_{i}$

Lastly, Eqs. 9 - 11 are then used to obtain the $95 \%$ confidence interval:

$$
\begin{aligned}
& \operatorname{Var}(\theta)=\theta^{2} \frac{\frac{1}{L}+\frac{\operatorname{var}(\pi)}{\pi^{2}}}{\left(1+\frac{\operatorname{var}(\pi)}{\pi^{2}}\right)^{2}} \\
& \operatorname{se}(\theta)=\sqrt{\operatorname{var}(\theta)} \\
& 95 \% C I=\theta \pm 1.96 * \operatorname{se}(\theta)
\end{aligned}
$$

\section{Results}

\section{Safety Evaluation of RLC's}

Descriptive characteristics for the RLC and comparison sites are displayed in Table 1. Independent variables included the intersection's logarithmic mean AADT across all approaches, mean speed limit \& mean number of lanes for the major and minor roads, along with their ranges, standard deviations, and $95 \%$ confidence intervals. Table 2 presents the mean annual collision frequency during the before and after periods for the RLC and comparison sites. Four categories of collisions were considered: Rightangle/turn, rear-end, all injury, and RLR-related injury collisions.

As illustrated in Table 2, mean annual right-angle/turn intersection collisions at comparison sites were similar during the before and after periods while RLC sites experienced a slight decline (-7.4\%) after camera enforcement. Rear-end mean annual intersection collisions increased for both site types during the after period, however, the magnitude of increase at the comparison sites were nearly twice that of the camera enforced intersections. In comparison, all injury and RLR-related injury mean annual 
intersection collisions declined for both site types after camera enforcement commenced. Camera enforced sites, however, experienced a slightly greater decline in both all injury and RLR-related injury mean annual intersection collisions versus comparison sites.

On July 1st, 2012, all law enforcement agencies were required to report additional crashes which were not previously necessary to submit. Therefore, statutory changes in crash reporting may have influenced the increase in right-angle/turn and rear-end crashes during the after period. Conversely, since crash reports are mandated for injury collisions, their frequency was likely not affected by the statutory change.

To examine the impact of increased crash reporting during 2012, two groups of SPF's were developed. The first group comprised crash data for the period $2008-2011$ while the second group also included 2012. Table 3 summarizes the SPF's for the 40 comparison intersections using a NB regression model. As shown in Table 3, greater traffic flow and higher minor approach speed limits resulted in increases of rightangle/turn, rear-end, all injury, and RLR-related injury collisions. Moreover, rear-end crash frequency were also affected by higher speed limits at major approaches and greater number of lanes at minor approaches. The overdispersion parameter's $95 \%$ confidence interval did not overlap zero for any of the SPF's, suggesting that the NB distribution was appropriate for each model. The observational before-after EB method was subsequently applied to the 20 RLC intersections using each SPF. The aggregate safety effectiveness for right-angle-turn, rear-end, all injury, and RLR-related injury collisions at the 20 RLC are presented in Table 4 for one and two years after camera enforcement. 
During the first year, the RLC sites experienced a marginal decrease (-3\%) in right-angle/turn collisions (119 observed collisions vs. 123 expected). In contrast, a significant increase in rear-end collisions $(+40 \%)$ was observed at the RLC sites (302 actual collisions vs. 215 expected) according to the EB analysis. When injury collisions were considered, there was a significant decline in all injury (-19\%) and RLR-related injury $(-24 \%)$ collisions at the camera sites during the first year of enforcement. All injury collisions, however, were barely significant according to the index of effectiveness's $95 \%$ confidence interval.

As expected, the statutory change in reporting during 2012 resulted in an increase in collisions at the RLC sites after two years despite camera enforcement. According to Table 4 , right-angle/turn and rear-end crashes at the camera sites increased by $14 \%$ and $51 \%$, respectively than what would otherwise had been expected. Similar to the first year, results indicated a statistically significant increase in rear-end collisions and a nonsignificant effect on right-angle/turn collisions. Despite the increase in overall rear-end and right-angle/turn collisions, a significant reduction in RLR-related injury crashes (-17\%) was still observed. The EB analysis indicated an expected 190 RLR-related collisions would occur after two years across the 20 RLC sites if no treatment had been applied, yet, only 158 collisions actually occurred. A decline in all injury collisions $(-12 \%)$ was also noted, however, unlike the first year, this result was not significant. Despite these declines, the magnitude of reduction was lower compared to year one. Since reporting of injury collisions were likely not affected by the statutory changes, the decreasing trend in all-injury and RLR-related injury collisions observed during the second year may have resulted from a potential "novelty effect" at the camera sites. 


\section{Discussion}

This study summarized the results of a before-after EB analysis to evaluate the effects of RLC enforcement in Miami-Dade County during 2011-2012. The results from this evaluation suggest that RLC enforcement reduce RLR-related injury collisions but increase rear-end collisions. These findings were consistent with other studies which also found safety benefits from the enforcement of RLCs when using Bayesian methodologies.

Changes in crash reporting requirements likely resulted in an increase in the magnitude of rear-end collisions and a slight increase in right-angle/turning collisions after two years of camera enforcement. Results suggest, however, that the effect of RLC's on right-angle/turning crashes is minimal, even with changes in reporting. The possible existence of a "novelty effect" may have also influenced results since increases in the frequency of both all-injury and RLR-related injury collisions was observed during the second year of enforcement, although this could not be verified.

The decision to select crashes occurring within 150 versus 250 feet likely increased sensitivity (i.e. identifying true intersection crashes), yet doing so likely resulted in some collisions being missed. It was felt that using a 250 foot distance would misclassify several collisions as an intersection crash, thus potentially biasing the number

of incidents towards the mean. Determining which distance was more appropriate required detailed examination of crash reports, which was not available in our study. The Florida Department of Transportation defines an intersection crash as one which occurs within 250 feet of an intersection. Miami-Dade County, however, is a large urban area with many adjacent streets located within 250 feet of an intersection, especially within 
major roads. Vehicles can easily exit these arterials by turning into oncoming traffic, resulting in some incidents being erroneously classified as an intersection crash. Thus, the sensitivity of an intersection crash was increased by lowering the buffer distance to 150 feet. Various radii have been used to define intersection crashes, with results varying depending on the distance used (Wang et al., 2008). It has been recommended that 150 feet would simplify case computations for urban areas with a higher density street network (Miller, 2011). Previous studies have also used a 150 foot radius to select target crashes (Council et al., 2005; Persaud et al., 2005; Miller, 2011; Kweon, 2007). This study was able to address for many of the limitations found in previous RLC evaluations. By employing an EB analysis, the effect of RTM was controlled for which may overestimate results. Additionally, by using three years of crash data prior to camera enforcement, the impact of RTM was further reduced. It has previously been suggested that several years of crash data is required to properly employ an EB analysis (Hauer 1997; Hauer et al. 2002). A period of at least three years crash data is recommended with no significant changes in external factors to the observation sites, which was applied in this study. We also attempted to control for spillover by using comparison intersections located within the same community, but at a specified distance from any RLC site. The spillover effect was minimized by selecting comparison sites at least two miles from an RLC intersection, but likely not completely eliminated. The possibility of some drivers being influenced to avoid running non-RLC sites still exists. If some spillover was present, the results of this study may have underestimated the benefit of RLCs. If completely controlled for, however, the RLCs may have shown an even greater significant safety benefit. A drawback of using large buffer zones, however, is that it 
become more difficult to match the treated intersections for unobservable characteristics such as weather (Wong, 2014). Accordingly, a follow-up study using smaller buffer zones to select comparison sites should be considered.

A limitation of this study was the small number of injury crashes at each site. This was expected since injury crashes are rare events. Approximately $29 \%$ of all crashes in the United States resulted in at least one injury/fatality during 2011 (NHTSA, 2012). In this study, two or three additional crashes might have influenced the results if few sites (4 -5 intersections) had been examined, however, by selecting a larger number of sites with RLCs, this impact was reduced. Due to the low frequency of severe injury/fatal crashes, we were unable to further separate incidents by injury severity. In our analysis, there was less than one fatal/severe injury crash per intersection annually during the 5 -year period. It has been found that fatal crashes make up only $0.87 \%$ of all injury collisions (Wong, 2014) therefore a statistical analysis was unfeasible since doing so would have created difficulty in estimating the safety effect. A possibility to address this limitation is to analyze the effect of RLC's on injury severity using multiple cities. A second limitation was a lack of different intersection types within our analysis. All but one of the intersections analyzed were four-legged. As a result, we could not assess whether 3legged or crossing intersections would be more beneficial for RLC installation. Therefore, additional research is recommended since they may bring about differing RLC effects.

Additional possibilities to further evaluate the safety benefit of RLCs would be to increase the number of crashes by examining a greater number of intersections or lengthening the study period. If using a longer study period however, one must be aware 
that any changes made to a site (e.g., increased number of lanes, yellow timing changes) during the period of analysis may be more likely, rendering the results of that site invalid. In closing, the results of this analysis provided some conclusive results, particularly RLCs showed a benefit in reducing RLR-related injury collisions in MiamiDade County at camera sites after enforcement commenced, yet its tradeoff was a large increase in rear-end collisions. There was inconclusive evidence though, whether RLC's affected the incidence of right-angle/turning and all injury collisions. The statutory changes in crash reporting during the second year of camera enforcement clearly affected our results, specifically the incidence of right-angle and rear-end collisions, nevertheless, a "novelty effect" should also not be ruled out. Future research should consider some of the unintended events encountered in this study, particularly crash reporting changes and small frequencies of fatal/severe injury collisions when conducting RLC analyses. 


\section{References}

Ahmed MM. \& Abdel-Aty M. Evaluation and spatial analysis of automated red-light running enforcement cameras. Transportation Research Part C. 2014:1-10. In Press http://dx.doi.org/10.1016/j.trc.2014.07.012

Abdel-Aty, M., Yan, X. \& Radwan, E. Characteristics of rear-end collisions at signalized intersections using multiple logistics model. Accident Analysis and Prevention. 2005; 37(6):983-995.

Bonneson J \& Zimmerman K. Federal Highway Administration. Developmment of guidelines for identifying and treating locations with a red light running problem. 2004. Report Number FHWA/TX-05/0-4196-2.

Burkey M. \& Obeng K. A detailed investigation of crash risk reduction resulting from red light cameras in small urban areas. Greensboro, NC: North Carolina Agricultural and Technical State University. 2004; Available at: http://www.ncat.edu/ traninst/Burkey Obeng Updated Report 2004.pdf. Accessed September 7, 2014.

Council FM, Persaud B, Eccles K, et al. Federal Highway Administration. Safety Evaluation of Red Light Cameras. 2005; Report Number FHWA-HRT-05-048. Federal Highway Administration. Safety at Signalized Intersections (Short Version). 2010. Available at http://safety.fhwa.dot.gov/intersection/signalized/presentations/sign_int_pps0515 08/short/). Accessed July 5th, 2014.

Florida Department of Transportation, Transportation Statistics Office. Florida Traffic Online Site. Available at http://www2.dot.state.fl.us/FloridaTrafficOnline/viewer.html.Accessed May 30, 2014.

Florida Department of Transportation, Transportation Statistics Office. Geographic Information Systems Website. Available at http://www.dot.state.fl.us/planning/statistics/gis/. Accessed May 30, 2014.

Garber, NJ, Miller, JS, Abel, RE, Eslambolchi, S, Korukonda, SK. The impact of red light cameras (photo-red enforcement) on crashes in Virginia. Report no. VTRC 07-R2. Charlottesville, VA: Virginia Transportation Research Council. 2007; Available at: http://www.virginiadot.org/vtrc/main/online reports/pdf/07-r2.pdf. Accessed September 7, 2014.

Insurance Institute for Highway Safety. Status Report, Vol. 42, No. 1, Jan 2007. Available at: http://www.iihs.org/externaldata/srdata/docs/sr4201.pdf. Accessed June $4^{\text {th }}, 2014$. 
Insurance Institute for Highway Safety. Red Light Running. 2014. Available at: http://www.ihs.org/iihs/topics/t/red-light-running/topicoverview. Accessed June $17^{\text {th }}, 2014$.

Hallmark S, Orellana M, McDonald T, et al. Red light running in Iowa: Automated enforcement program evaluation with Bayesian analysis. Transportation Research Record. 2010; 2182:48-54.

Hauer E. Observational Before-after Studies in Road Safety: Estimating the Effect of Highway and Traffic Engineering Measures on Road Safety. 1997; Pergamon, Elsevier Science Ltd., Oxford, United Kingdom.

Hauer E, Harwood DW, Council FM, et al. Estimating safety by the empirical Bayes method: a tutorial. Transportation Research Record. 2002; 1784:126-131.

Hillier W, Ronczka J, Schnerring F. An evaluation of red light cameras in Sydney. 1993; Research Note 1/93, Road Safety Bureau, Roads and Traffic Authority, New South Wales, Australia.

Karlaftis MG \& Golias I. Effects of road geometry and traffic volumes on rural roadway accident rates. Accident Analysis and Prevention. 2002; 34(3):357-365.

Ko M, Geedipally SR, Walden TD. Effectiveness and Site Selection Criteria for Red Light Camera Systems. Transportation Research Record. 2013; No. 2327:53-60.

Kyrychenko SY. \& Retting RA. Review of "A Detailed Investigation of Crash Risk Reduction Resulting from Red Light Cameras in Small Urban Areas" by M. Burkey and K. Obeng. Insurance Institute for Highway Safety. 2004; Available at: http://www.iihs.org/research/topics/pdf/r1034.pdf. Accessed April 17, 2013.

Kweon YJ. Development of a safety evaluation procedure for identifying high-risk signalized intersections in the Virginia Department of Transportation's Northern Virginia District. Report No. FHWA/VTRC 08-R1. Charlottesville, VA: Virginia Transportation Research Council. 2007; Available at: http://www.virginiadot.org/vtrc/main/online reports/pdf/08-r1.pdf. Accessed September 7, 2014.

Lord D \& Mannering F. The statistical analysis of crash-frequency data: A review and assessment of methodological alternatives. Transportation Research Part A: Policy and Practice. 2010; 44(5):291-305. 
Mann T, Brown S, Coxon C. Evaluation of the effects of installing red light cameras at selected Adelaide Intersections. 1994; Report Series 7/97, Office of Road Safety, South Australian Department of Transport, Walkerville, South Australia.

McGee HW, Eccles KA. The impact of red-light camera enforcement on crash experience. A synthesis of highway practice. 2003; Available at: http://www.nhtsa.gov/DOT/NHTSA/Traffic\%20Injury\%20Control/Articles/Assoc iated\%20Files/HS810763.pdf. Accessed December 10, 2012.

Miami-Dade County. Geographic Information Systems Self Services Website. Available at http://www.miamidade.gov/technology/gis-self-service.asp). Accessed May 30, 2014.

Miller JS. Pilot implementation of a resource guide to enhance the incorporation of safety into the regional planning process. Report No. FHWA/VCTIR 12-R8.

Charlottesville, VA: Virginia Center for Transportation Innovation and Research. 2011; Available at: http://www.virginiadot.org/vtrc/main/online reports/pdf/12$\underline{\text { r8.pdf }}$

National Highway Traffic Safety Administration, National Center for Statistics and Analysis, US Department of Transportation. 2001. Traffic Safety Facts 2000. A Compilation of Motor Vehicle Crash Data from the Fatality Analysis Reporting System and the General Estimates System. Available at: http://wwwnrd.nhtsa.dot.gov/Pubs/TSF2000.pdf. Accessed July 5th, 2014.

National Highway Traffic Safety Administration. Mathematical Analysis Division, National Center for Statistics and Analysis. Crash Factors in Intersection-Related Crashes: An On-Scene Perspective. 2010; Report Number DOT HS 811366.

National Highway Traffic Safety Administration National Center for Statistics and Analysis, U.S. Department of Transportation. (2011). Traffic Safety Facts 2009. A Compilation of Motor Vehicle Crash Data from the Fatality Analysis Reporting System and the General Estimates System. Available at: http://wwwnrd.nhtsa.dot.gov/pubs/811402ee.pdf. Accessed July 5th, 2014.

National Highway Traffic Safety Administration. National Center for Statistics and Analysis, U.S. Department of Transportation. (2014). Traffic Safety Facts 2012. A Compilation of Motor Vehicle Crash Data from the Fatality Analysis Reporting System and the General Estimates System. Report Number: DOT HS 812032. Available at: http://www-nrd.nhtsa.dot.gov/pubs/812032.pdf. Accessed October 30, 2014. 
National Highway Traffic Safety Administration National Center for Statistics and Analysis, U.S. Department of Transportation. (2012). Traffic Safety Facts 2011. A Compilation of Motor Vehicle Crash Data from the Fatality Analysis Reporting System and the General Estimates System. Report Number: DOT HS 811754. Available at: http://www-nrd.nhtsa.dot.gov/Pubs/811754AR.pdf. Accessed September 5th, 2014.

Persaud B, Council FM, Lyon C, et al. Multijurisdictional Safety Evaluation of Red Light Cameras. Transportation Research Record: Journal of the Transportation Research Board. 2005; Vol 1922:29-37.

Retting RA \& Williams AF, "Characteristics of Red Light Violators: Results of a Field Investigation," Journal of Safety Research 1996; 27.1, 9-15.

Retting RA, Williams AF, Farmer CM, et al. Evaluation of red light camera enforcement in Fairfax, Virginia. Institute of Transportation Engineers. 1999a; 69(8):30-34.

Retting RA, Williams AF, Farmer CM, et al. Evaluation of red light camera enforcement in Oxnard, California. Accident Analysis and Prevention. 1999b; 31(3):169-174.

Retting RA \& Kyrychenko SY. Reductions in injury crashes associated with red light camera enforcement in Oxnard, California. American Journal of Public Health. 2002; 92(11):1822-1825.

Retting RA, Ferguson SA, \& Hakkert, AS. Effects of red light cameras on violations and crashes: A review of the international literature. Traffic Injury Prevention. 2003; $4(1): 17-23$.

Shin K. \& Washington S. The impact of red light cameras on safety in Arizona. Accident Analysis and Prevention. 2007; 39(6):1212-1221.

Wang X, Abdel-Aty M, Nevarez A, \& Santos JB. Investigation of safety influence area for four-legged signalized intersections nationwide survey and empirical inquiry. Transportation Research Record: Journal of the Transportation Research Board, 2008; No. 2083. 86-95.

Wong T. Lights, camera, legal action! The effectiveness of red light cameras on collisions in Los Angeles. Transportation Research Part A: Policy and Practice. 2014; 69:165-182. 
Figures and Tables

\begin{tabular}{|c|c|c|c|c|c|}
\hline \multicolumn{6}{|c|}{ (AADT) } \\
\hline Intersections & $\begin{array}{c}\text { Mean (1000's) } \\
2008-2012\end{array}$ & Range (1000's) & $\begin{array}{l}\text { Standard } \\
\text { Deviation }\end{array}$ & $\begin{array}{c}95 \% \\
\text { Confidence } \\
\text { Interval }\end{array}$ & p-value \\
\hline $\begin{array}{l}\text { Red Light } \\
\text { Cameras } \\
(\mathrm{n}=20)\end{array}$ & 67.79 & $(26.25,114.70)$ & 24.90 & $(56.14,79.44)$ & 0.80 \\
\hline $\begin{array}{c}\text { Comparison } \\
(\mathrm{n}=40)\end{array}$ & 66.23 & $(30.83,108.40)$ & 21.22 & $(59.44,73.01)$ & \\
\hline \multicolumn{6}{|c|}{ (Speed Limit - Major Road) } \\
\hline Intersections & Mean & Range & $\begin{array}{l}\text { Standard } \\
\text { Deviation }\end{array}$ & $\begin{array}{c}95 \% \\
\text { Confidence } \\
\text { Interval }\end{array}$ & p-value \\
\hline $\begin{array}{c}\text { Red Light } \\
\text { Cameras } \\
(\mathrm{n}=20)\end{array}$ & 38.75 & $(30.00-45.00)$ & 3.93 & $(36.91,40.59)$ & 0.06 \\
\hline $\begin{array}{c}\text { Comparison } \\
(\mathrm{n}=40)\end{array}$ & 40.56 & $(35.00-45.00)$ & 1.92 & $(39.95,41.18)$ & \\
\hline \multicolumn{6}{|c|}{ (Speed Limit - Minor Road) } \\
\hline Intersections & $\begin{array}{l}\text { Mean Speed } \\
\text { Limit }\end{array}$ & Range & $\begin{array}{l}\text { Standard } \\
\text { Deviation }\end{array}$ & $\begin{array}{c}95 \% \\
\text { Confidence } \\
\text { Interval } \\
\end{array}$ & p-value \\
\hline $\begin{array}{c}\text { Red Light } \\
\text { Cameras } \\
(\mathrm{n}=20)\end{array}$ & 35.25 & $(30.00,42.50)$ & 4.28 & $(33.24,37.26)$ & 0.01 \\
\hline $\begin{array}{c}\text { Comparison } \\
(\mathrm{n}=40)\end{array}$ & 37.81 & $(30.00,40.00)$ & 3.36 & $(36.74,38.89)$ & \\
\hline \multicolumn{6}{|c|}{ (Number of Lanes - Major Road) } \\
\hline Intersections & Mean & Range & $\begin{array}{l}\text { Standard } \\
\text { Deviation }\end{array}$ & $\begin{array}{c}95 \% \\
\text { Confidence } \\
\text { Interval } \\
\end{array}$ & p-value \\
\hline $\begin{array}{c}\text { Red Light } \\
\text { Cameras } \\
(\mathrm{n}=20)\end{array}$ & 5.25 & $(4.00-6.00)$ & 0.97 & $(4.80,5.70)$ & 0.34 \\
\hline $\begin{array}{c}\text { Comparison } \\
(\mathrm{n}=40)\end{array}$ & 4.95 & $(2.00-7.00)$ & 1.22 & $(4.56,5.34)$ & \\
\hline \multicolumn{6}{|c|}{ (Number of Lanes - Minor Road) } \\
\hline Intersections & Mean & Range & $\begin{array}{l}\text { Standard } \\
\text { Deviation }\end{array}$ & $\begin{array}{c}95 \% \\
\text { Confidence } \\
\text { Interval } \\
\end{array}$ & p-value \\
\hline $\begin{array}{c}\text { Red Light } \\
\text { Cameras } \\
(\mathrm{n}=20)\end{array}$ & 3.60 & $(2.00-6.00)$ & 0.88 & $(3.19,4.01)$ & 0.50 \\
\hline $\begin{array}{c}\text { Comparison } \\
(\mathrm{n}=40)\end{array}$ & 3.78 & $(2.00-6.00)$ & 0.97 & $(3.46,4.09)$ & \\
\hline
\end{tabular}




\begin{tabular}{|c|c|c|c|c|}
\hline \multicolumn{5}{|c|}{$\begin{array}{c}\text { Table 3.2 Manuscript 3: Mean crash frequency for red light camera and comparison sites } \\
\text { during before and after periods }\end{array}$} \\
\hline $\begin{array}{l}\text { Intersection } \\
\text { Type }\end{array}$ & Crash Type & $\begin{array}{l}\text { Intersection } \\
\text { Annual Mean } \\
\text { Crash Frequency } \\
\text { Before Period } \\
(\mathbf{2 0 0 8}-\mathbf{2 0 1 0})\end{array}$ & $\begin{array}{c}\text { Intersection Annual } \\
\text { Mean Crash } \\
\text { Frequency After } \\
\text { Period } \\
(2011-2012)\end{array}$ & $\begin{array}{c}\text { Percent } \\
\text { Change } \\
\text { Before-After } \\
\text { Period }\end{array}$ \\
\hline \multirow[t]{4}{*}{ RLC's } & Right-Angle/Turn & 7.47 & 6.92 & $-7.4 \%$ \\
\hline & Rear-End & 13.85 & 16.78 & $+21.2 \%$ \\
\hline & All Injury & 5.62 & 4.60 & $-18.1 \%$ \\
\hline & $\begin{array}{l}\text { RLR-Related } \\
\text { Injury }\end{array}$ & 5.03 & 3.95 & $-21.5 \%$ \\
\hline \multirow[t]{4}{*}{ Comparison } & Right-Angle/Turn & 4.75 & 4.79 & $+0.84 \%$ \\
\hline & Rear-End & 7.41 & 10.40 & $+40.4 \%$ \\
\hline & All Injury & 6.44 & 6.00 & $-6.8 \%$ \\
\hline & $\begin{array}{l}\text { RLR-Related } \\
\text { Injury }\end{array}$ & 5.89 & 5.01 & $-18.1 \%$ \\
\hline
\end{tabular}




\begin{tabular}{|c|c|c|c|c|c|c|c|c|}
\hline SPF & Crash Type & Intercept & $\begin{array}{l}\text { Ln } \\
\text { (AADT) }\end{array}$ & $\begin{array}{l}\text { Speed } \\
\text { Limit }_{\text {maj }}\end{array}$ & $\begin{array}{l}\text { Speed } \\
\text { Limit }_{\text {min }}\end{array}$ & LaneS $_{\text {maj }}$ & LaneS $_{\min }$ & $\begin{array}{l}\text { Dispersion } \\
\text { Parameter }\end{array}$ \\
\hline $\mathrm{SPF} 1_{\mathrm{a}}$ & Right-Angle/Turn & -10.855 & $1.121^{*}$ & -0.025 & $0.075^{*}$ & 0.048 & -0.181 & 0.169 \\
\hline $\mathrm{SPF} 1_{\mathrm{b}}$ & Rear-End & -21.108 & $1.555^{*}$ & $0.111^{*}$ & $0.070^{*}$ & 0.162 & $-0.218^{*}$ & 0.146 \\
\hline $\mathrm{SPF} 1_{\mathrm{c}}$ & All Injury & -11.650 & $1.061^{*}$ & 0.110 & $0.734^{*}$ & 0.092 & -0.159 & 0.121 \\
\hline$S P F 1_{d}$ & RLC Injury & -11.972 & $1.114^{*}$ & -0.001 & $0.077^{*}$ & 0.113 & -0.187 & 0.128 \\
\hline $\mathrm{SPF} 2_{\mathrm{a}}$ & Right-Angle/Turn & -11.552 & $1.146^{*}$ & -0.017 & $0.083^{*}$ & 0.045 & -0.174 & 0.160 \\
\hline $\mathrm{SPF} 2 \mathrm{~b}$ & Rear-End & -22.141 & $1.645^{*}$ & $0.116^{*}$ & $0.079 *$ & 0.122 & $-0.219^{*}$ & 0.150 \\
\hline $\mathrm{SPF} 2_{\mathrm{c}}$ & All Injury & -11.938 & $0.985^{*}$ & 0.373 & $0.083^{*}$ & 0.075 & -0.162 & 0.129 \\
\hline $\mathrm{SPF} 2_{\mathrm{d}}$ & RLC Injury & -12.192 & $1.027^{*}$ & 0.025 & $0.085^{*}$ & 0.106 & -0.187 & 0.134 \\
\hline
\end{tabular}

SPF 1 - SPF for period $2008-2011$

SPF 2 - SPF for period $2008-2012$

* - Denotes statistical significance at the $95 \%$ level. 


\begin{tabular}{|c|c|c|c|c|c|c|}
\hline \multicolumn{7}{|c|}{ Table 3.4 Manuscript 3: Safety effectiveness of red light camera sites by collision type } \\
\hline $\begin{array}{c}\text { Years After } \\
\text { Enforcement }\end{array}$ & Crash Type & $\begin{array}{l}\text { Expected } \\
\text { Collisions } \\
\end{array}$ & $\begin{array}{l}\text { Observed } \\
\text { Collisions } \\
\end{array}$ & $\begin{array}{l}\text { Index Of Effectiveness } \\
(\% \text { Reduction/Increase })\end{array}$ & $\begin{array}{c}\text { Standard } \\
\text { Error }\end{array}$ & 95\% C.I. \\
\hline \multirow{4}{*}{ 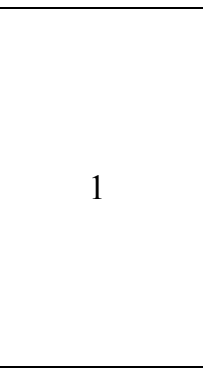 } & $\begin{array}{c}\text { Right- } \\
\text { Angle/Turning }\end{array}$ & 123 & 119 & $0.97(-3.2 \%)$ & 0.10 & $(0.78,1.16)$ \\
\hline & Rear-End & 215 & 302 & $1.40 *(+40.2 \%)$ & 0.09 & $(1.22,1.58)$ \\
\hline & All Injury & 106 & 86 & $0.81 *(-19.1 \%)$ & 0.09 & $(0.62,0.99)$ \\
\hline & $\begin{array}{l}\text { RLR-Related } \\
\text { Injury }\end{array}$ & 96 & 73 & $0.76^{*}(-24.3 \%)$ & 0.10 & $(0.57,0.94)$ \\
\hline \multirow{4}{*}{2} & $\begin{array}{c}\text { Right- } \\
\text { Angle/Turning }\end{array}$ & 243 & 277 & $1.14(+13.6 \%)$ & 0.08 & $(0.97,1.30)$ \\
\hline & Rear-End & 445 & 671 & $1.51 *(+50.7 \%)$ & 0.08 & $(1.36,1.66)$ \\
\hline & All Injury & 209 & 184 & $0.88 \quad(-12.2 \%)$ & 0.08 & $(0.73,1.03)$ \\
\hline & $\begin{array}{l}\text { RLR-Related } \\
\text { Injury }\end{array}$ & 190 & 158 & $0.83 *(-17.2 \%)$ & 0.08 & $(0.68,0.98)$ \\
\hline
\end{tabular}




\section{CHAPTER V}

\section{CONCLUSIONS}

This research revealed the following major findings:

1. The literature review found that although red light camera studies showed decreases in violations, collisions, and injuries, many contained methodological shortcomings, thus a greater number of studies were needed to strengthen the conclusion that they reduce the incidence of motor vehicle crashes and related injuries.

2. The literature review also found that although spillover effects appeared to be evident for red light camera studies, many of the jurisdictions examined were small in area. Thus, it was unknown whether spillover resulting from red light camera enforcement would have similar effects in large metropolitan areas.

3. The literature review found that several red light camera studies examined violations as an outcome variable. To properly assess the safety impact of red light cameras, however, the incidence of right-angle, rear-end, and injury collisions should be examined.

4. Analysis of the forty comparison intersections revealed that the negative binomial distribution was a better fit compared to a poisson model. The negative binomial model achieved a Scaled Deviance/DF of 1.22 and a Pearson Chi-Squared/DF ratio of 1.09. In contrast, the Poisson model resulted in a scaled deviance/DF and chi square/DF ratios of 5.17 and 5.06, respectively. The log likelihood ratio for the two models resulted in a chi 
square value of 76.14 suggesting that the negative binomial distribution was a better fitting model.

5. The negative binomial distribution also provided a better fit compared to the gamma distributed model. The scaled deviance/DF and log-likelihood values for both models were similar, however, the gamma model's Pearson ChiSquare/DF ratio was only 0.24 . In addition, the AIC value for the gamma model (304.53) was slightly higher in comparison to the negative binomial model (303.92). The overdispersion parameter value for the negative binomial model was $0.16,95 \% \mathrm{CI}(0.09,0.29)$. The gamma model's dispersion parameter $(\alpha)$ was estimated to be $0.23,95 \% \mathrm{CI}(0.15,0.35)$, indicating overdispersion was present.

6. After one year of camera enforcement, red light cameras showed a benefit in reducing RLR-related injury collisions at camera sites (-24\%), yet its tradeoff was a large increase in rear-end collisions $(+38 \%)$. There was inconclusive evidence whether RLC's affected right-angle/turning and all injury collisions. Statutory changes in crash reporting during the second year of camera enforcement likely caused an increase in the incidence of right-angle $(+14 \%)$ and rear-end collisions $(+51 \%)$, however, decreases in red light related injury collisons (-17\%) were still observed. A "novelty effect", however, could not be ruled out.

7. These data suggest that red light cameras reduced the incidence of red light running associated collisions. The drawback of RLCs, however, is an increase 
in rear-end collisions, which although less severe than right-angle collisons, can still result in minor injuries.

\section{Directions for future research}

The results of the present study are intended to enhance research regarding the effectiveness of red light cameras in reducing injury collisions. The data analyzed indicates that motor vehicle related injury collisons is a major area of interest for research regarding red light cameras. Our results suggest that injury collisons may decrease after red light camera enforcement of intersections. Despite this incidence, there was an increase in specific types of collisions (e.g. rear-end crashes). In addition, it was difficult to assess whether camera enforcement reduced injuries according to severity due to small sample sizes. Thus, more studies exploring and elucidating the role of red light cameras on injury severity is needed. Hence, a study which measures, in addition to overall injury incidence, minor/major injuries and fatalities are needed. The most effective manner of implementing these types of studies would be to extend the duration or increase the number of intersections examined.

Other methodologies which could enhance this study would be to examine additional factors which were unavailable including impaired drivers, seat belt usage. These and other factors such as weather may influence the incidence of injury collisions. Lastly, since newer methodological approaches regarding motor vehicle collisions are constantly being developed, future research may more accurately determine the effectiveness of red light cameras on injury and other collision types. 


\section{CHAPTER VI}

\section{LIST OF REFERENCES}

Abdel-Aty M.A. \& Radwan E.A. (2000). Modeling traffic accident occurrence and involvement. Accident Analysis and Prevention, 32(5), 633-642.

Abdel-Aty, M., Yan, X. \& Radwan, E (2005). Characteristics of rear-end collisions at signalized intersections using multiple logistics model. Accident Analysis and Prevention. 37(6):983-995.

Awadzi KD, Classen S, Hall A, Duncan RP, Garvan CW. (2008). Predictors of injury among younger and older adults in fatal motor vehicle crashes. Accident Analysis and Prevention, 40(6), 1804-1810.

Balkin S \& Ord J. (2001). Assessing the impact of speed-limit increases on fatal interstate crashes. Journal of Transportation and Statistics, 4(1), 1-12.

Barnett AG, van der Pols JC, \& Dobson AJ. (2005). Regression to the mean: what it is and how to deal with it. International Journal of Epidemiology, 34(1):215-220.

Bonneson, J. \& Zimmerman, K. Effect of yellow-interval timing on the frequency of red light violations at urban intersections. Transportation Research Board, Washington, DC. 2004; 1865:20-27.

Bonneson J \& Zimmerman K. Federal Highway Administration. Development of guidelines for identifying and treating locations with a red light running problem. 2004. Report Number FHWA/TX-05/0-4196-2.

Brimley BK, Saito M, Shultz GG. (2012). Safety performance function development of new models for rural two-lane, two-way highways. Transportation Research Record: Journal of the Transportation Research Board, 2279, 82-89.

Burkey M. \& Obeng K. (2004). A detailed investigation of crash risk reduction resulting from red light cameras in small urban areas. Greensboro, NC: North Carolina Agricultural and Technical State University. Available at: http://www.ncat.edu/ traninst/Burkey_Obeng_Updated_Report 2004.pdf. Accessed April 17, 2013.

Cameron AC \& Trivedi PK. Regression Analysis of Count Data. Cambridge University Press, Cambridge, MA, 1988.

Centers for Disease Control and Prevention (CDC). WISQARS (Web-based Injury Statistics Query and Reporting System). (2011a). Retrieved from http://www.cdc.gov/injury/wisqars. 
Centers for Disease Control and Prevention (CDC). (2011b). Vital Signs: Nonfatal, motor vehicle-occupant injuries (2009) and seat belt use (2008) among adults - United States. Morbidity and Mortality Weekly Report, 59(51), 1673-1720.

Chen HY, Senserrick T, Martiniuk ALC, Ivers IQ, Boufous S, ... Norton R. (2010). Fatal crash trends for Australian young drivers 1997-2007: Geographic and socioeconomic differentials. Journal of Safety Research, 41(2), 123-128.

Council FM \& Stewart JR (2000). Safety Effects of the conversion of rural two-lane to four-lane roadways. ITE Journal, 70(4), 37-42.

Edquist J, Rudin-Brown C, Lenne MG. (2009). Road design factors and their interactions with speed and speed limits. Monash University Accident Research Centre. ISBN 0732623865. ISSN 1835-4815. Report \#298.

Elvik R. (2008). Dimensions of road safety problems and their measurement. Accident Analysis and Prevention, 40(3), 1200-1210.

Elvik R. (2012). Speed limits, enforcement, and health consequences. Annual Review of Public Health, 33, 225-238.

Erke, A. (2009). Red light for red-light cameras? A meta-analysis of the effects of redlight cameras on crashes. Accident Analysis and Prevention, 41(5), 897-905.

Federal Highway Administration - U.S. Department of Transportation (2014). Safety at Signalized Intersections - Short Version. Retrieved from http://safety.fhwa.dot.gov/intersection/signalized/presentations/sign int pps0515 08/short/index.cfm.

Federal Highway Administration (2005). Safety evaluation of red light cameras, an executive summary. Publication No: FHWA-HRT-05-049. Retrieved from http://www.fhwa.dot.gov/publications/research/safety/05049/.

Ferguson, C. J., \& Brannick, M.T. Publication bias in psychological science: Prevalence, methods for identifying and controlling and implications for the use of metaanalyses. Psychological Methods. 2012; 17(1): 120-128.

Freedman M \& Esterlitz JR (1990). Effects of the 65-mph speed limit on speeds in three states. Transportation Research Record: Journal of the Transportation Research Board, 1281, 52 -61. 
Garber, NJ, Miller, JS, Abel, RE, Eslambolchi, S, Korukonda, SK. (2007). The impact of red light cameras (photo-red enforcement) on crashes in Virginia. Report no. VTRC 07-R2. Charlottesville, VA: Virginia Transportation Research Council. Available at: http://www.virginiadot.org/vtrc/main/online_reports/pdf/07-r2.pdf. Accessed April 17, 2013.

Greibe P (2003). Accident prediction models for urban roads. Accident Analysis and Prevention, 35(2), 273-285.

Hall JW \& Hurtado M. (1992). Effect of intersection congestion on accident rates. Transportation Research Record: Journal of the Transportation Research Board, 1376, 71-77.

Hallmark S, Orellana M, McDonald T, Fitzsimmons E, Matulac. Red light running in Iowa: Automated enforcement program evaluation with Bayesian analysis. Transportation Research Record. 2010; 2182:48-54.

Harwood DW, Council FM, Hauer E, Hughes WE, Vogt A. (2000). Prediction of the expected safety performance of rural two-lane highways. Federal Highway Administration. Report No: FHWA-RD-99-207.

Hauer E. (1997). Observational Before-after Studies in Road Safety: Estimating the Effect of Highway and Traffic Engineering Measures on Road Safety. Pergamon, Elsevier Science Ltd., Oxford, United Kingdom

Hillier W, Ronczka J, Schnerring F. (1993). An evaluation of red light cameras in Sydney. Research Note 1/93, Road Safety Bureau, Roads and Traffic Authority, New South Wales, Australia.

Hu MC, Pavlicova M, Nunes EV. Zero-inflated and hurdle models of count data with extra zeros: examples from an HIV-risk reduction intervention trial. American Journal of Drug Alcohol Abuse. 2011; 37(5):367-75.

Huang H, Chin H.C, \& Mazharul, H. Severity of driver injury and vehicle damage in traffic crashes at intersections: A Bayesian hierarchical analysis. Accident Analysis and Prevention. 2008; 40 (1):45-54.

Insurance Institute for Highway Safety. Red Light Running. 2014. Available at: http://www.ihs.org/iihs/topics/t/red-light-running/topicoverview

Insurance Institute for Highway Safety (2013). Automated Enforcement Laws. Available at http://www.iihs.org/laws/automated_enforcement.aspx. Accessed April 17, 2013. 
Insurance Institute for Highway Safety. Status Report, 2007; 42(1), Available at: http://www.iihs.org/externaldata/srdata/docs/sr4201.pdf

Joksch HC (1993). Velocity change and fatality risk in a crash - A rule of thumb. Accident Analysis and Prevention, 25(1), 103-104.

Jovanis PP \& Chang HL. Modeling the relationship of accidents to miles traveled. Transportation Research Record. 1986; 1068:42-51.

Karlaftis MG \& Golias I. Effects of road geometry and traffic volumes on rural roadway accident rates. Accident Analysis and Prevention. 2002; 34(3):357-365.

Khan HMR, Saxena A, Rana S, Ahmed NU. Bayesian method for modeling male breast cancer survival data. Asian Pacific Journal Cancer Prevention. 2014a; 15(2), 663-669.

Khan HFR, Saxena A, Ross E, Ramamoorthy V, Sheehan D. Inferential statistics from Black Hispanic breast cancer survival data. The Scientific World Journal of Probability and Statistics. 2014b. Available at: http://www.hindawi.com/journals/tswj/aip/604581/, 1 - 13.

Kyrychenko SY. \& Retting RA. (2004). Review of "A Detailed Investigation of Crash Risk Reduction Resulting from Red Light Cameras in Small Urban Areas" by M. Burkey and K. Obeng. Insurance Institute for Highway Safety. Available at: http://www.iihs.org/research/topics/pdf/r1034.pdf. Accessed April 17, 2013.

Lord D, Washington S, Ivan J. (2005). Poisson, poisson-gamma, abd zero-inflated regression models of motor vehicle crashes: balancing statistical fit and theory. Accident Analysis and Prevention, 37(1), 35-46.

Lord D \& Mannering F. (2010). The statistical analysis of crash-frequency data: A review and assessment of methodological alternatives. Transportation Research Part A: Policy and Practice. 44(5):291-305.

Mann T, Brown S, Coxon C. (1994). Evaluation of the effects of installing red light cameras at selected Adelaide Intersections. Report Series 7/97, Office of Road Safety, South Australian Department of Transport, Walkerville, South Australia.

Martinez, KL, Porter, BE. Characterizing red light runners following implementation of a photo enforcement program. Accident Analysis and Prevention. 2006; 38(5):86270 . 
McGee HW, Eccles KA. The impact of red-light camera enforcement on crash experience. A synthesis of highway practice. 2003. Available at:http://www.nhtsa.gov/DOT/NHTSA/Traffic\%20Injury\%20Control/Articles/As sociated\%20Files/HS810763.pdf.

Mehta G \& Lou Y (2013). Calibration and development of safety performance functions for Alabama. Transportation Research Record: Journal of the Transportation Research Board, 2398, 75-82.

Miaou SP \& Lum H. (1993). Modeling vehicle accidents and highway geometric design relationships. Accident Analysis and Prevention. 25(6), 689-709.

Milton JC \& Mannering FL. (1998). The relationship among highway geometrics, trafficrelated elements and motor-vehicle accident frequencies, Transportation 25(4), 395-413.

National Highway Traffic Safety Administration. National Center for Statistics and Analysis, U.S. Department of Transportation. (2014). Traffic Safety Facts 2012. A Compilation of Motor Vehicle Crash Data from the Fatality Analysis Reporting System and the General Estimates System. Report Number: DOT HS 812032. Available at: http://www-nrd.nhtsa.dot.gov/pubs/812032.pdf.

National Highway Traffic Safety Administration National Center for Statistics and Analysis U.S. Department of Transportation (2013). Traffic Safety Facts 2011. A Compilation of Motor Vehicle Crash Data from the Fatality Analysis Reporting System and the General Estimates System. Report No: DOT HS 811754. Retrieved from http://www-nrd.nhtsa.dot.gov/Pubs/811754AR.pdf

National Highway Traffic Safety Administration National Center for Statistics and Analysis U.S. Department of Transportation (2012). Alcohol Impaired Driving. Report No: DOT HS 811 700. Retrieved from http://wwwnrd.nhtsa.dot.gov/Pubs/811700.pdf

National Highway Traffic Safety Administration. U.S. Department of Transportation. (2011a). 2010 Motor Vehicle Crashes, an Overview. Available at: http://wwwnrd.nhtsa.dot.gov/Pubs/811552.pdf. Accessed September 10, 2012.

National Highway Traffic Safety Administration National Center for Statistics and Analysis, U.S. Department of Transportation. (2011b). Traffic Safety Facts 2009. A Compilation of Motor Vehicle Crash Data from the Fatality Analysis Reporting System and the General Estimates System. Available at: http://wwwnrd.nhtsa.dot.gov/pubs/811402ee.pdf. Accessed August 24, 2012. 
National Highway Traffic Safety Administration - National Center for Statistics and Analysis, U.S. Department of Transportation. (2010a). Distracted Driving 2009. Report No: DOT HS 811 379. Retrieved from http://www.distraction.gov/research/PDF-Files/Distracted-Driving-2009.pdf

National Highway Traffic Safety Administration - National Center for Statistics and Analysis, U.S. Department of Transportation. (2010b). Crash Factors in Intersection-Related Crashes: An On-Scene Perspective. Report No: DOT HS 811 366. Retrieved from http://www-nrd.nhtsa.dot.gov/Pubs/811366.pdf

National Highway Traffic Safety Administration National Center for Statistics and Analysis U.S. Department of Transportation. (2001). Traffic Safety Facts 2000. A Compilation of Motor Vehicle Crash Data from the Fatality Analysis Reporting System and the General Estimates System. Report No: DOT HS 809337. Retrieved from www-nrd.nhtsa.dot.gov/Pubs/TSF2000.pdf

Naumann RB, Dellinger AM, Zaloshnja E, Lawrence BA, \& Miller TR. Incidence and total lifetime costs of motor vehicle-related fatal and nonfatal injury by road user type, United States, 2005. Traffic Injury Prevention. 2010; 11(4):353-60.

Nicaj L, Wilt S, \& Henning K. Motor vehicle crash pedestrian deaths in New York City: the plight of the older pedestrian. Journal of Injury Prevention. 2006; 12(6):414416.

Noland RB \& Oh L (2004). The effect of infrastructure and demographic change on traffic-related fatalities and crashes: A case study of Illinois County-Level data. Accident Analysis and Prevention, 36(4), 525-532.

Oh J, Washington SP, Nam D. Accident prediction model for railway-highway interfaces. Accident Analysis and Prevention. 2006; 38(2): 346-356.

Papaioannou P. Driver behaviors, dilemma zone and safety effects at urban signalized intersections in Greece. Accident Analysis \& Prevention. 2007; 39(1):147-158.

Persaud B, Council FM, Lyon C, Eccles K, Griffith M. (2005). Multijurisdictional Safety Evaluation of Red Light Cameras. Transportation Research Record: Journal of the Transportation Research Board. Vol 1922:29-37.

Persaud BN, Retting RA, Lyon C, McCartt AT. (2008). Review of "The Impact of Red Light Cameras (Photo-Red Enforcement) on Crashes in Virginia" by Nicholas J. Garber, John S. Miller, R. Elizabeth Abel, Saeed Eslambolchi, and Santhosh K. Korukonda. Insurance Institute for Highway Safety. Available at: http://www.iihs.org/research/topics/pdf/r1100.pdf. Accessed April 17, 2013. 
Porter BE \& England KJ. (2000). Predicting red-light running behavior: A traffic safety study in three urban settings. Journal of Safety Research, 31(1), 1-8.

Qin X, Ivan JN, Ravishanker N. (2004). Selecting exposure measures in crash rate prediction for two-lane highway segments. Accident Analysis and Prevention, 36(2), 183-191.

Read TRC \& Cressie N. Goodness-of-Fit Statistics for Discrete Multivariate Data. Springer-Verlag, New York, 1988.

Renski H, Khattak AJ, Council FM. (1999). Effect of speed limit increases on crash injury severity: analysis of single-vehicle crashes on North Carolina Interstate highways. Transport Research Record: Journal of the Transportation Research Board, 1665, 100-108.

Retting R.A, Williams A.F, Preusser D.F, \& Weinstein H.B. (1995). Classifying urban crashes for countermeasure development. Accident Analysis and Prevention, 27(3), 283-294.

Retting RA \& Greene MA (1997). Traffic speeds following the repeal of the national maximum speed limit. ITE Journal, 67, 42-46.

Retting RA, Williams AF, Farmer CM, \& Feldman AF. (1999a) Evaluation of red light camera enforcement in Fairfax, Virginia. Institute of Transportation Engineers. 69(8):30-34.

Retting R.A, Ulmer R.G, \& Williams A.F. (1999b). Prevalence and characteristics of red light running crashes in the United States. Accident Analysis and Prevention, 31(6), 283-294.

Retting RA, Williams AF, Farmer CM, \& Feldman AF (1999c). Evaluation of red light camera enforcement in Oxnard, California. Accident Analysis and Prevention. 31(3):169-174.

Retting R.A \& Kyrychenko S.Y. (2002). Reductions in injury crashes associated with red light camera enforcement in Oxnard, California. American Journal of Public Health, 92(11), 1822-1825.

Retting R.A \& Ferguson S.A. (2003). Effects of red light cameras on violations and crashes: A review of the international literature. Traffic Injury Prevention, 4(1), 17-23.

Romano E, Tippens S, \& Voas R. (2005). Fatal Red Light Crashes: The Role of Race and Ethnicity. Accident Analysis and Prevention. 37(3):453-460. 
Shin K. \& Washington S. (2007). The impact of red light cameras on safety in Arizona. Accident Analysis and Prevention, 39(6), 1212-1221.

Shiner D. (1998). Speed and crashes: A controversial topic and an elusive relationship. Transportation Research Board Special Report, 254, 221-276.

Solomon D. (1964). Accidents on main rural highways related to speed, driver, and vehicle. Washington DC: Federal Highway Administration.

Spicer R, Miller T, Langley J, \& Stephenson, S. (2005). Comparison of injury case fatality rates in the United States and New Zealand. Injury Prevention. 2005; 11(2):71-76.

United States Census Bureau. State and County QuickFacts. 2012. Available at: http://quickfacts.census.gov/qfd/index.html. Accessed November 21, 2012.

US Department of Transportation, Federal Highway Administration. 2001. Revised assessment of economic impacts of implementing minimum levels of pavement marking retroreflectivity. Report Number: FHWA-SA-10-016.

Vernon DD, Cook LJ, Peterson KJ, Dean M. (2004). Effect of repeal of the national maximum speed limit law on occurrence of crashes, injury crashes, and fatal crashes on Utah highways. Accident Analysis and Prevention, 36(2), 223-229.

Wahl GM, Islam T, Gardner B, Marr AB, Hunt JP, McSwain NE, Baker CC, Duchesne J. (2010). Red light cameras: do they change driver behavior and reduce accidents? J Trauma. 68(3):515-518.

Walden T. \& Bochner B. (2011). Effectiveness of red light cameras - Texas Statewide Evaluation. ITE Journal. 81: 30 - 33.

Wang X \& Abdel-Aty M. (2006). Temporal and spatial analyses of rear-end crashes at signalized intersections. Accident Analysis and Prevention. 38(6), 1137-1150.

Wang, X. \& Abdel-Aty, M. (2008). Modeling left-turn crash occurrence at signalized at signalized intersections by conflicting patterns. Accident Analysis and Prevention. 2008; 40(1):76-88.

West SK, Hahn DV, Baldwin KC, Duncan DD, Munoz BE, Turano KA, . . BandeenRoche, K. Older drivers and failure to stop at red lights. Journal of Gerontology. 2010; 65(2):179-183.

Winklemann R. Duration dependence and dispersion in count-data models. Journal of Business \& Economic Statistics. 1995a; 13(4):467-474. 
Winklemann R \& Zimmermann KF. Recent developments in count data modelling: Theory and application. Journal of Economic Surveys. 1995b; 9(1):1-20.

Wong T. Lights, camera, legal action! The effectiveness of red light cameras on collisions in Los Angeles. Transportation Research Part A: Policy and Practice. 2014; 69:165-182.

World Health Organization (WHO). (2013). Global status report on road safety 2013. Retrieved from http://www.who.int/violence injury prevention/road safety status/2013/en/index html

World Health Organization (2009). Global status report on road safety: time for action. Available at:

http://www.who.int/violence_injury prevention/road_safety_status/2009.

Yan X, Radwam E, Abdel-Aty M. (2005). Characteristics of rear-end accidents at signalized intersections using a multiple logistic regression model. Accident Analysis and Prevention. 37(6), 983-995.

Ye Z, Zhang Y, Lord D. Goodness-of-fit testing for accident models with low means. Accident Analysis and Prevention. 2013; 61:78-86.

Zaloshnja E. \& Miller TR. (2009). Cost of crashes related to road conditions, United States, 2006. Annals of Advances in Automotive Medicine/Annual Scientific Conference. 53:141-153. 
VITA

ANTHONI F LLAU JR

EDUCATION AND EMPLOYMENT

1995-1999 Bachelor of Science in Nutrition

Florida International University

Miami, Florida

2003-2005 Masters of Public Health

Graduate Certificate in Epidemiology

Florida International University

Miami, Florida

2005-2007 Lead Poisoning Epidemiologist

Florida Department of Health

Miami-Dade County, Florida

2007-2015 Epidemiologist

Florida Department of Health

Miami-Dade County, Florida

2009-2015 Ph.D. Candidate, Public Health

Specialization in Epidemiology

Florida International University

Miami, Florida

\section{PUBLICATIONS AND PRESENTATIONS}

Llau AF, Ahmed N, Khan H, Cevallos F, Pekovic V (2015 - In Press). The impact of red light cameras on crashes within Miami-Dade County. Traffic Injury Prevention: In Press

Llau AF, Ahmed N. (2014). The effectiveness of red light cameras in the United States, A literature review. Traffic Injury Prevention: 15(6):542-50

Mann P, O'Connell EK, Zhang G, Llau A, Rico E, Leguen F. (2011). Alert system to detect possible school-based outbreaks of influenza-like illness. Emerging Infectious Diseases: 17(2):262-264.

O'Connell EK, Zhang G, Leguen F, Llau A, Rico E (2010) Innovative Uses for Syndromic Surveillance. Emerging Infectious Diseases: 16(4):669-671 
Guest Presenter, Practicum Epidemiology Methods, Florida International

University - Miami, Florida (2011 - 2015) 